\title{
Aircraft Observations of a Coastally Trapped Wind Reversal off the California Coast
}

\author{
Thomas R. Parish, David A. Rahn, and David Leon \\ Department of Atmospheric Science, University of Wyoming, Laramie, Wyoming
}

(Manuscript received 12 March 2007, in final form 17 May 2007)

\begin{abstract}
The summertime marine atmospheric boundary layer off the California coast is normally characterized by northerly winds associated with the Pacific high. This pattern is occasionally disturbed by episodes of southerly winds and a finger of fog or low stratus adjacent to the coastline extending approximately $100 \mathrm{~km}$ offshore. These events propagate northward along the coast with speeds between 5 and $12 \mathrm{~m} \mathrm{~s}^{-1}$ and have a life span of several days. These occurrences have been referred to as coastally trapped wind reversals (CTWRs), coastally trapped disturbances, or southerly surges. The CTWR event of 22-25 June 2006 was explored by the University of Wyoming King Air research aircraft to document the physical characteristics of the wind reversal in an attempt to infer the forcing mechanisms responsible for the propagation. Two flights from 23 June are presented that are representative of the CTWR during its mature stage. Sawtooth maneuvers depict the CTWR vertical structure, and isobaric legs directly measure the horizontal pressure gradient force (PGF). Observations showed a thickening of the CTWR layer in an alongshore direction to the south. The inversion layer varies throughout the day with the final sawtooth leg depicting clear dynamic destabilization within the inversion layer. A PGF is present at the head of the CTWR that is directed northward. No significant PGF was detected in the cross-shore direction, suggesting that for this case there is little variation in the depth of the marine boundary layer normal to the coast.
\end{abstract}

\section{Introduction}

During summer the marine atmospheric boundary layer (MBL) off the West Coast is controlled by the Pacific high that is typically situated several hundred kilometers to the west. The time-averaged sea level pressure field over the eastern Pacific Ocean adjacent to the U.S. coastline consists of isobars that run roughly parallel to the coastline (Mass and Albright 1987), and northerly or northwesterly winds prevail in the boundary layer. Low-level jets frequently are found with a maximum near the top of the MBL (e.g., Zemba and Friehe 1987; Beardsley et al. 1987; Rogers et al. 1998; Pomeroy and Parish 2001). Subsidence arising from the Pacific high establishes a sharp temperature inversion at the top of the well-mixed MBL that has been shown to increase to the west. This normal north wind regime in the summertime MBL becomes disrupted at times and is replaced by southerly wind events that have a

Corresponding author address: Thomas R. Parish, Department of Atmospheric Science, University of Wyoming, Laramie, WY 82071.

E-mail: parish@uwyo.edu

DOI: $10.1175 / 2007$ MWR2199.1

(C) 2008 American Meteorological Society time period on the order of several days. These cases have been referred to as coastally trapped wind reversals (CTWRs), coastally trapped disturbances (CTDs), or southerly surges. Bond et al. (1996) and Mass and Bond (1996) have examined the synoptic-scale circulations associated with CTWRs and note that on average one to two events occur per summertime month. In addition to the wind reversal, CTWR characteristics include coastal fog that extends in a narrow band on the order of $100 \mathrm{~km}$ wide adjacent to the coast. A concise summary of CTWRs is presented in Nuss et al. (2000).

CTWRs have been discussed by a number of authors. Dorman (1985) was among the first to describe a CTWR, interpreting the event as a Kelvin wave. Mass and Albright (1987) also described CTWR events and suggest that the propagation occurs in response to the mesoscale pressure field that consists of an alongshore pressure gradient force directed to the north. The authors also note that some CTWRs may move as a topographically trapped density current. Ralph et al. (2000) have examined the 10-11 June 1994 CTWR, for which the most comprehensive dataset exists, and note that that the large-scale environment associated with reversals possibly includes a cyclonic circulation that 
extends from the surface to above the top of the MBL. They conclude that the MBL changes accompanying the CTWR seem to support an internal bore. Ralph et al. (2000) examined the primary means by which reversals propagate and suggest that CTWRs are best characterized as a hybrid of motions referred to as a mixed Kelvin wave bore.

Few in situ airborne measurements of CTWRs have been conducted. The 10-11 June 1994 CTWR was monitored by the University of North Carolina Piper Seneca III (Bane 1997; Nuss et al. 2000). CTWR episodes were also captured during the 1996 Coastal Waves experiment (Rogers et al. 1998), including the event of 21-22 July 1996, which is described in Nuss et al. (2000).

A number of modeling efforts have been conducted to simulate CTWRs and thereby examine questions as to the forcing for reversals (see Nuss et al. 2000 and references contained therein). Thompson et al. (1997) have numerically simulated the 10-11 June 1994 CTWR event, noting that the reversal can be best explained as a topographically trapped gravity current. Results from the modeling studies of Skamarock et al. (1999) capture winds in the near-coastal zone that resemble CTWRs. The authors conclude that variations in the depth of the MBL that are forced by onshore flow to the south of a mesoscale low are critical to the northward propagation of the CTWR.

The purpose of this paper is to present aircraft observations of the CTWR event of 22-25 June 2006 that occurred along the California coast. Geographic features of note in this region are shown in Fig. 1. This particular reversal was a "strong" event using the classification criteria described by Bond et al. (1996) and propagated from Point Conception to Cape Mendocino. Emphasis here is placed on the time period during which active northward propagation was present and for which time flights were conducted (viz., 23 June). Two flights using the University of Wyoming King Air (UWKA) research aircraft were conducted during that day to monitor the three-dimensional structure of the CTWR and to directly measure the horizontal pressure gradient forces in both alongshore and cross-shore directions.

\section{The 22-25 June 2006 CTWR overview}

As is the case for most CTWRs, a finger of stratus adjacent to the coast that is roughly coincident with the wind reversal is seen on visible satellite imagery. Figure 2 depicts the time series of four visible images taken daily at 0000 UTC starting on 22 June 2006 to show the

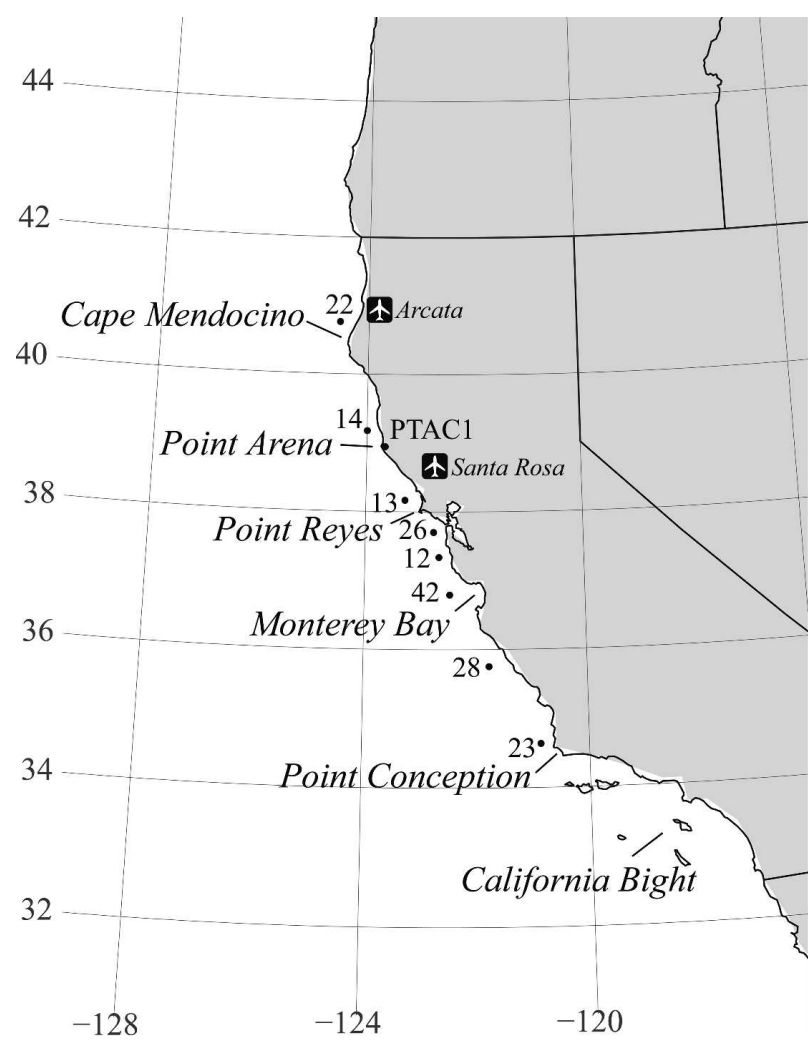

FIG. 1. Base map showing selected geographical features and buoy locations mentioned in text. Buoy numbers $\mathrm{xx}$ represent buoys numbered $460 x x$ by the NDBC.

CTWR evolution. Northward progression of the CTWR, as evidenced by the stratus clouds, has started by 0000 UTC 22 June (Fig. 2a). Satellite imagery is suggestive of a mesoscale cyclonic circulation to the west of Point Conception although the CTWR has a limited cross-shore extent. By 23 June (Fig. 2b) the CTWR is well developed and reaches past Monterey Bay. Evidence of a mesoscale cyclonic circulation is seen again to the west of Point Conception. The northward push of the CTWR reaches Point Arena by 0000 UTC 24 June (Fig. 2c) and Cape Mendocino by 0000 UTC 25 June (Fig. 2d). Note the cyclonic circulation is well depicted on 0000 UTC 24 June centered westsouthwest of the San Francisco Bay. As has been noted in the past (i.e., Bond et al. 1996), the most rapid movement of the CTWR takes place at night. During daytime hours, the northward advance of the CTWR is retarded and at times it appears to actually retreat southward.

CTWR formation requires an evolution of largerscale circulations to provide the necessary conditions in the near shore environment along the West Coast (Mass and Bond 1996; Nuss 2007). Foremost among these is the tendency for the ridging associated with the 

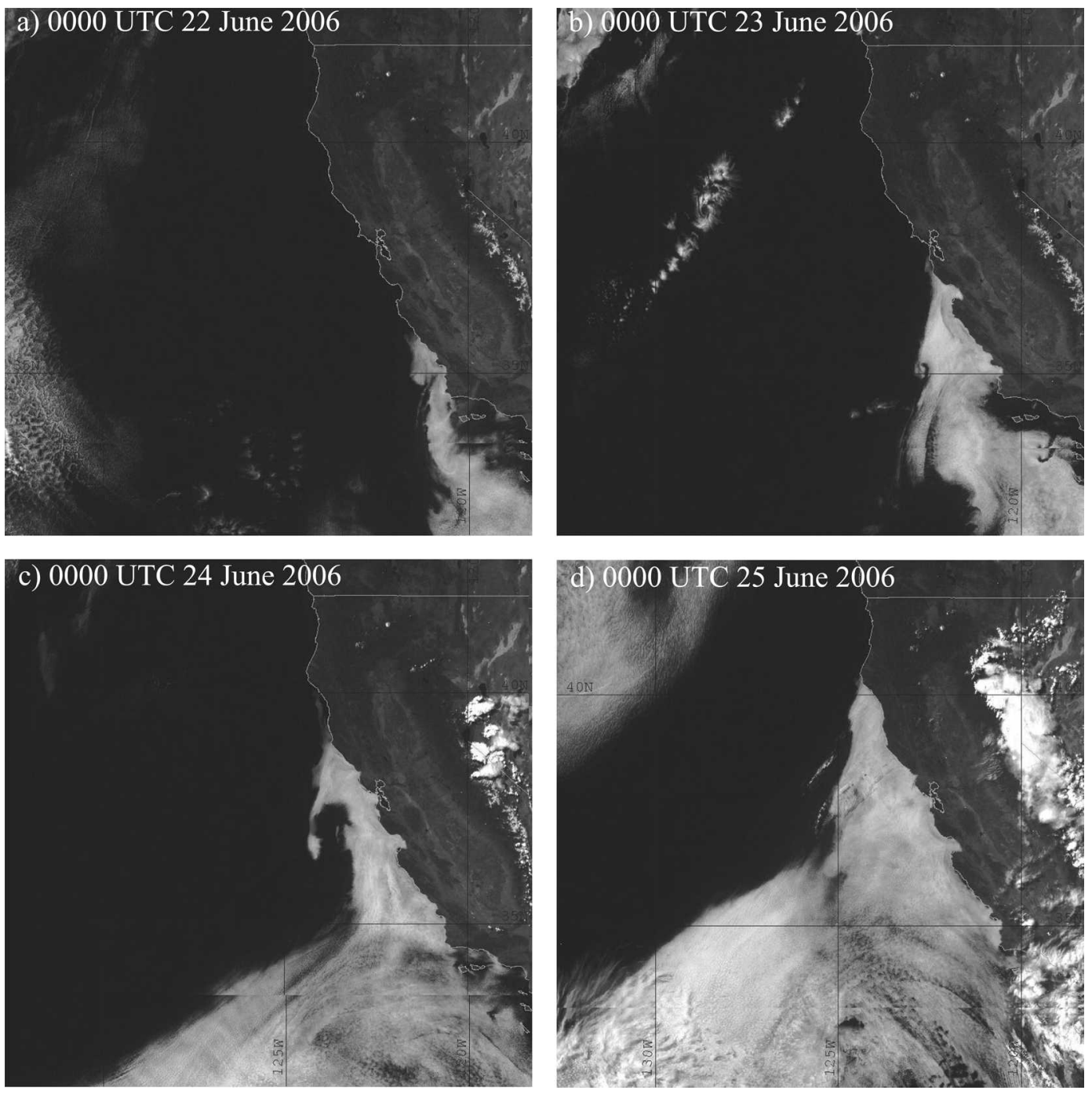

FIG. 2. Visible GOES-11 satellite imagery at 0000 UTC (a) 22, (b) 23, (c) 24, and (d) 25 Jun 2006. Images are from the Naval Research Laboratory.

Pacific high extending from the surface to approximately $850 \mathrm{hPa}$ to reach into the northwestern United States. The resulting pressure field supports significant low-level offshore flow across the northern California coastline. The offshore flow implies subsidence as the air moves across the sierra and coastal ranges and lee troughing becomes established. Anomalously warm temperatures occur with this strong offshore flow. The sequence of events during the 22-25 June CTWR follows this general pattern.

Meteorological conditions at the surface, 950-, 850-, and 500-hPa levels at 0000 UTC 21 June 2006 based on the Eta-218 (12-km resolution) 0000 UTC analysis grids are shown in Fig. 3. This time was prior to any northward progression of the CTWR although low stratus was seen in the California Bight region. The Pacific high extends into Oregon and Washington at the surface (Fig. 3a) and at $950 \mathrm{hPa}$ (Fig. 3b). Offshore flow of continental air is seen at the 950-hPa level and isotherms from the Eta model show that warm air had moved out over the Pacific off the central California coast. There is a suggestion of a cyclonic circulation at $850 \mathrm{hPa}$ (Fig. 3c) situated west of the California Bight that may reflect an extension of the thermal trough from the desert southwest. At $500 \mathrm{hPa}$ (Fig. 3d) a weak trough is situated to the east of California with ridging west of the coastline over the Pacific. A weak alongshore horizontal pressure gradient is found off the southern California coast from the surface through 500 $\mathrm{hPa}$. The alongshore pressure gradient force at the surface and at $950 \mathrm{hPa}$ intensifies significantly near the California-Oregon boundary that impedes the north- 

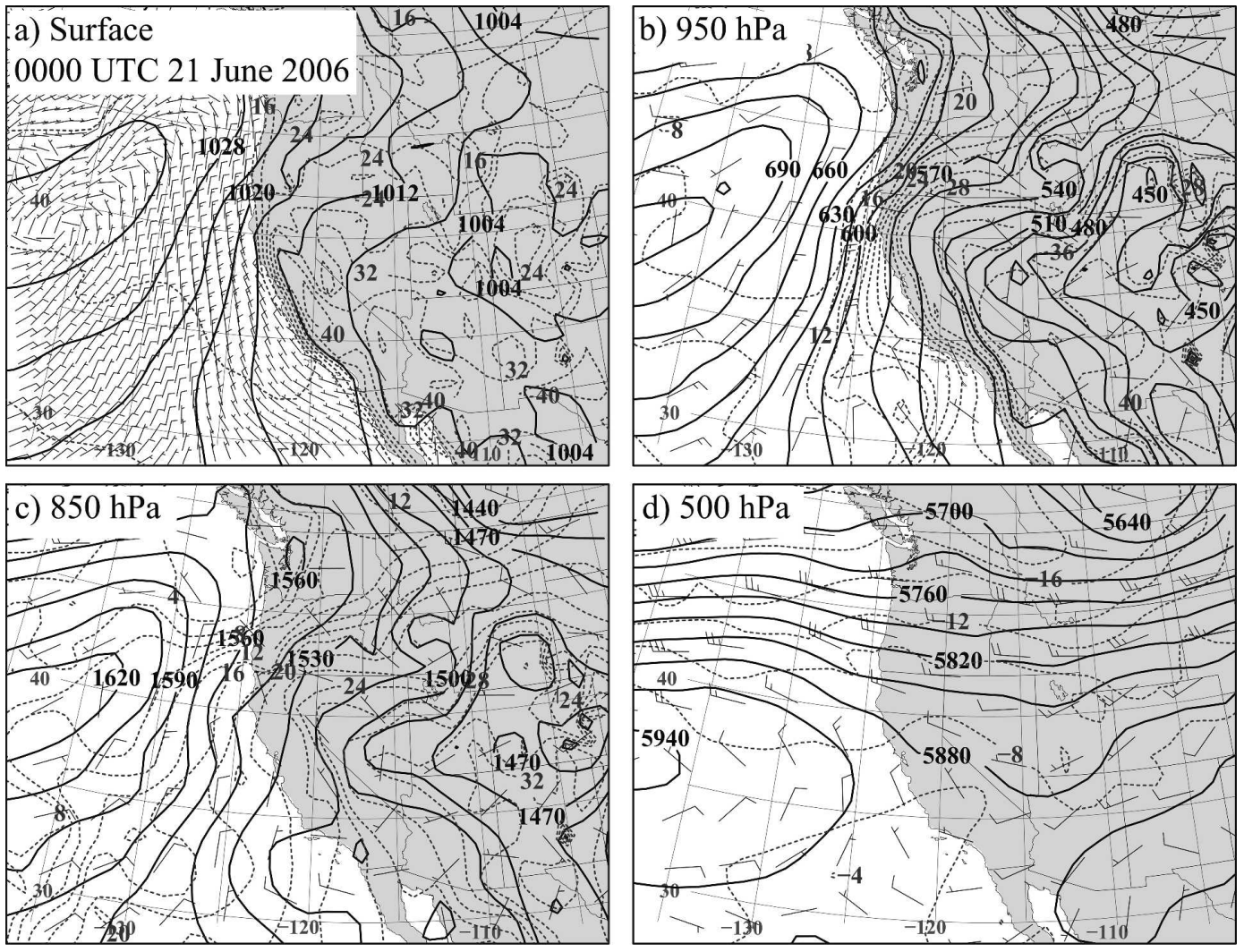

FIG. 3. Depictions of (a) sea level pressure (solid; hPa), surface temperature (dashed; ${ }^{\circ} \mathrm{C}$ ), and $10-\mathrm{m}$ wind barbs (kt; $1 \mathrm{kt} \approx 0.5 \mathrm{~m} \mathrm{~s}^{-1}$ ) over the ocean; (b) 950-hPa geopotential heights (solid; m), temperature (dashed; ${ }^{\circ} \mathrm{C}$ ), and wind barbs (kt); (c) 850-hPa geopotential heights (solid; m), temperature (dashed; ${ }^{\circ} \mathrm{C}$ ), and wind barbs (kt); and (d) 500-hPa geopotential heights (solid; m), temperature (dashed; ${ }^{\circ} \mathrm{C}$ ), and wind barbs (kt) based on 0000 UTC 21 Jun 2006 forecast from Eta 218 grids.

ward progress of the CTWR past approximately Cape Mendocino.

The CTWR began its northward progression late on 21 June and by 0000 UTC 22 June the finger of low stratus had reached the midway point between Point Conception and Monterey Bay. Figure 4 illustrates the meteorological conditions at the surface, 950-, 850-, and 500-hPa levels at 0000 UTC 22 June 2006 based on the Eta-218 analysis. Strong high pressure ridging into the Pacific Northwest continued from the surface to 850 $\mathrm{hPa}$ (Figs. 4a-c). The 10-m winds shown on the surface map suggest an extension of the thermal trough in the desert southwest extends out over the ocean to the west of Los Angeles, California. The horizontal pressure gradient at the surface over the ocean adjacent to the southern California coastline remains weak. Advection of warm, continental air reaches a maximum near 950 hPa west of San Francisco, California, and the isotherms show that the anomalously warm air has become situated over the Pacific. Near-record-high temperatures were present in the San Francisco Bay area including $39^{\circ} \mathrm{C}$ at Santa Rosa, California, and $33^{\circ} \mathrm{C}$ at the San Francisco Airport on 22 June. The $850-\mathrm{hPa}$ temperatures at 0000 UTC 22 June from the Eta analysis grids also show the effects of warm air advection with maximum temperatures in excess of $24^{\circ} \mathrm{C}$ to the west of Point Conception. A broad ridge of high pressure at $500 \mathrm{hPa}$ (Fig. 4d) is situated to the west of the central California coastline.

By 0000 UTC 23 June the southerly surge of coastal stratus had moved into Monterey Bay. Figure 5a shows the surface conditions at that time from the Eta analysis. A marked cyclonic circulation can be seen in the $10-\mathrm{m}$ winds to the west of Point Conception. Isotherms along the east side of the mesoscale cyclone are indicative of the southerly surge and the wind has a southerly component extending to central California. This is similar to the 9-10 June 1994 case study presented in Ralph et al. (1998) and discussed in Nuss et al. (2000). Cyclonic circulation can also be seen at the $950-\mathrm{hPa}$ level (Fig. 5b) and extending to the 850-hPa level (Fig. 5c). Satellite imagery (Figs. 2b,c) confirms the cyclonic cir- 

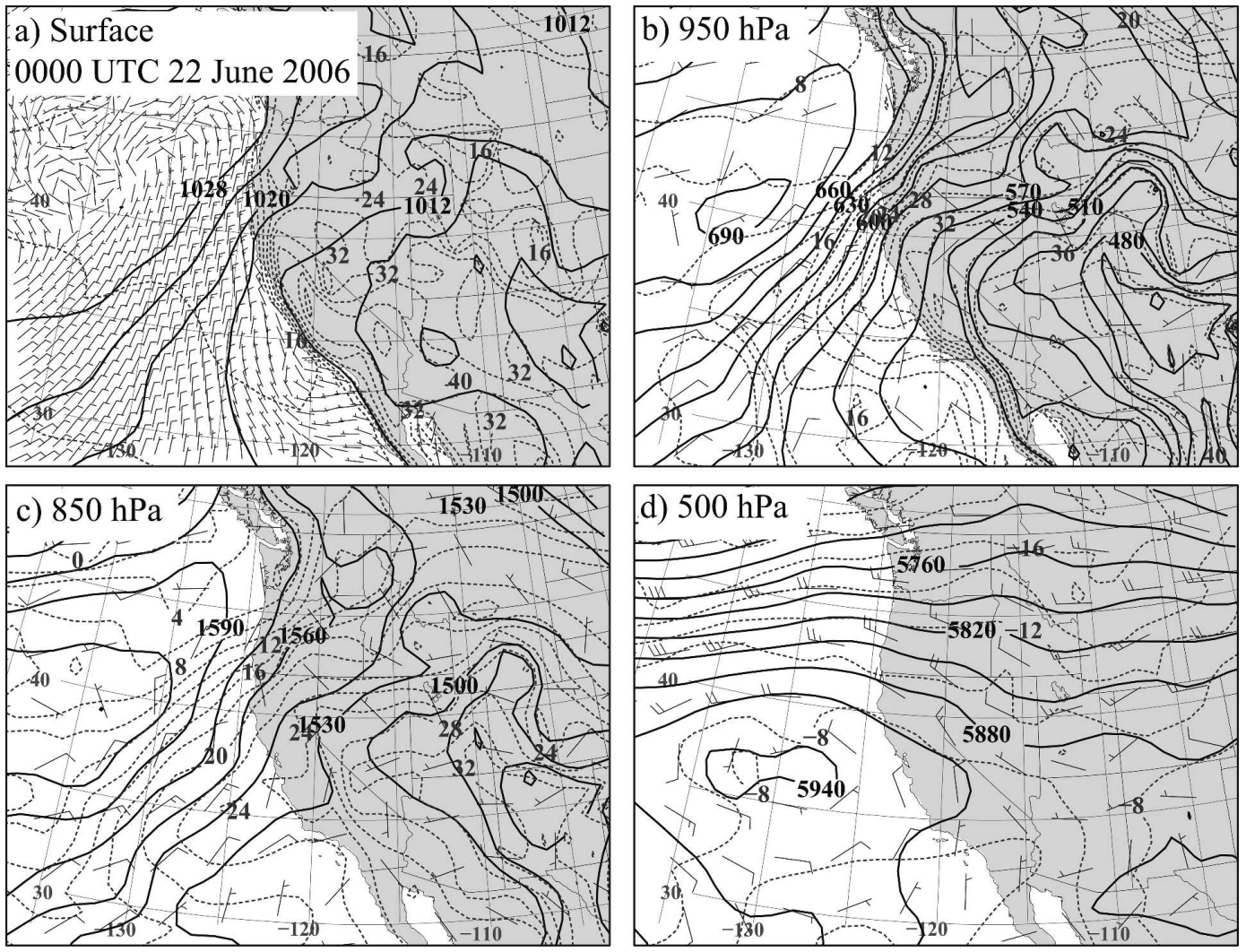

Fig. 4. As in Fig. 3, but for 22 Jun 2006.

culation that is present to the southwest of the leading edge of the CTWR. The ridge at $500 \mathrm{hPa}$ (Fig. 5d) has progressed eastward with the ridge axis on the West Coast.

By 0000 UTC 24 June the CTWR had moved north of the San Francisco Bay to near Point Arena. The cyclonic circulation that is obvious in the satellite image (Fig. 2c) is reflected in Fig. 6a as an elongated trough of low pressure off the central California coast. The CTWR presence in the Eta analysis can be identified by the isotherms at the surface and at $950 \mathrm{hPa}$ (Fig. 6b) that show cooler air moving northward along the California coastline. The 950-hPa heights indicate that the CTWR that is situated south of Cape Mendocino is reaching a pressure field adverse to the northward progress of the surge. Warm temperatures remain at 850 hPa offshore of the central California region (Fig. 6c).

Observations in the near-coastal region offshore from California are limited to fixed buoys and occasional ship reports. Buoys operated by the National Data Buoy Center (NDBC) provide data at hourly intervals and are shown in Fig. 1. Bond et al. (1996) and Ralph et al. (1998) have noted that CTWRs are often characterized by buoy data showing abrupt wind shifts, a rapid drop in temperature, and a rise in pressure.
Ralph et al. (1998) in their study of the 10-11 June 1994 CTWR showed from buoy data that the alongshore pressure gradient offshore from central California coast decreased from $5 \mathrm{hPa} 1000 \mathrm{~km}^{-1}$ to near zero prior to the CTWR development. Coincident with the surface high pressure amplification for the June 2006 CTWR shown in Figs. 3-6, NDBC buoys displayed a significant decrease in the alongshore pressure gradient in the days prior to the CTWR. Figure 7 illustrates the 0000 UTC pressure differences at buoys shown in Fig. 1 from the southernmost buoy 46023 at 24-h intervals for the week preceding the CTWR. On 17 June a strong north-south pressure gradient was present with highest pressures to the north. This alongshore pressure gradient relaxed considerably during the next $48 \mathrm{~h}$. By 0000 UTC 22 June the CTWR was just beginning to advance; the horizontal pressure field suggests a minimum in pressure just west of Monterey Bay at buoy 46042 with a net south-north alongshore pressure gradient to the north. The CTWR moved rapidly northward in response to the pressure field on 0000 UTC 23 June that reveals a reversed alongshore pressure gradient force that is directed south-north for all buoys south of Cape Mendocino.

Figure 8 illustrates the time series of meteorological 

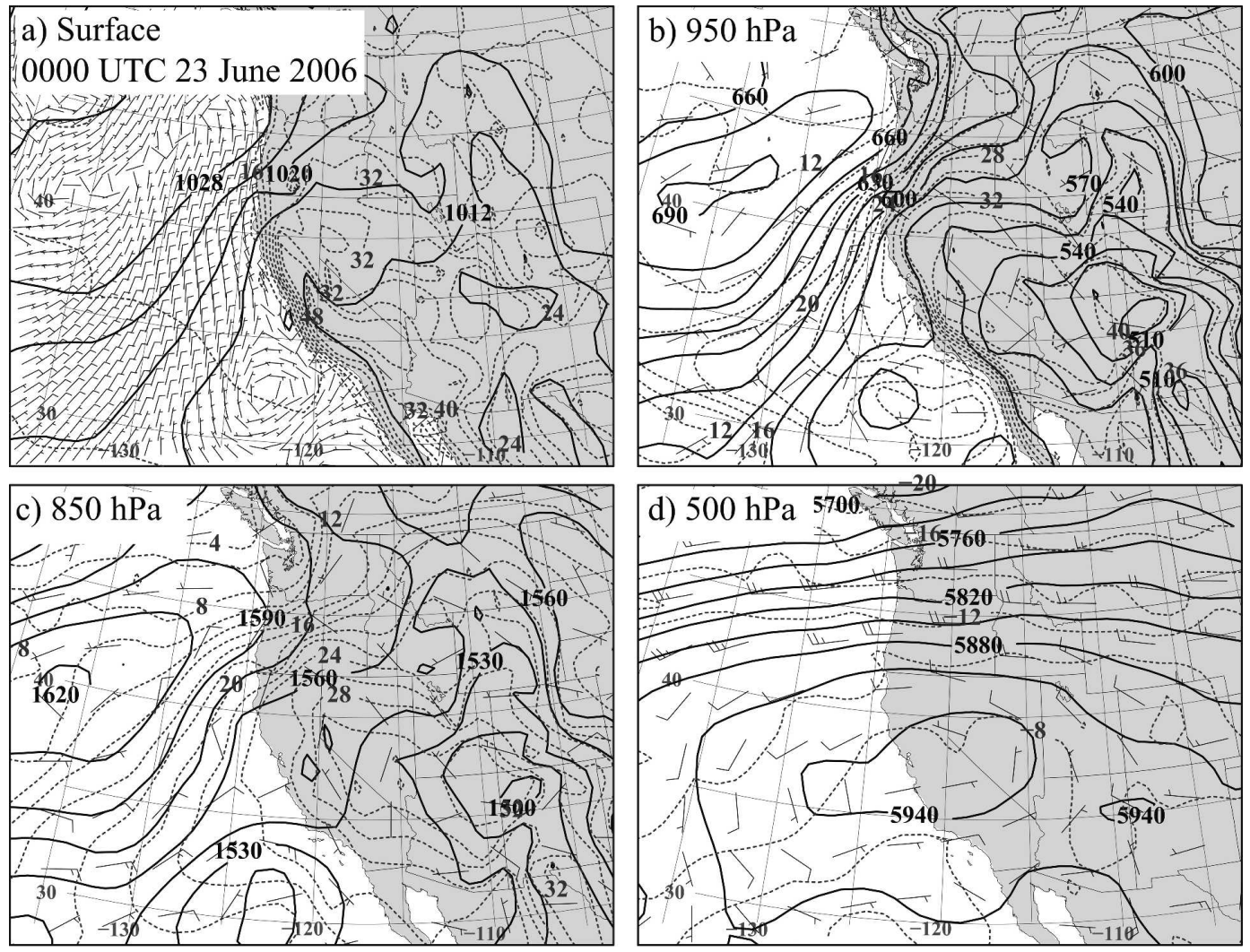

Fig. 5. As in Fig. 3, but for 23 Jun 2006.

conditions relative to the wind shift during this event at the individual NDBC buoys, as in Bond et al. (1996). One surface station on the coast near Point Arena (PTAC1) is included since the buoy here (46014) was not operational, and created a considerable data-void region between San Francisco and Cape Mendocino. The mean of the observations is represented by the thick dotted line. Pressure traces associated with the wind reversal (Fig. 8a) show that a change of about +2 $\mathrm{hPa}$ can be traced to the passage of the CTWR. Figure $8 \mathrm{~b}$ illustrates the variation in temperature through the passage of the CTWR and shows a small change with temperatures decreasing about $1^{\circ} \mathrm{C}$ on average over the $24 \mathrm{~h}$ centered at the reversal.

Passage of the CTWR is best seen in the wind direction (Fig. 8c) with winds reversing north-south at 1000 UTC 22 June for buoy 46028, 1800 UTC 22 June for buoy 46042, 0300 UTC 23 June for buoy 46012, 0800 UTC 23 June for buoy 46013, and 1100 UTC 23 June for PTAC1. The average wind speed (Fig. 8d) before the reversal is between 5 and $6 \mathrm{~m} \mathrm{~s}^{-1}$. After passage of the CTWR, wind speeds increase to $5-6 \mathrm{~m} \mathrm{~s}^{-1}$ within 8 $\mathrm{h}$ but then decrease gradually. The strongest wind associated with the reversal is found at the southernmost buoy and the land station. The wind is partitioned into alongshore and cross-shore components with the alongshore direction defined as $330^{\circ}$ and cross-shore as $60^{\circ}$, which has also been used by Ralph et al. (2000). The individual wind components (Figs. 8e,f) show that the alongshore component clearly dominates the changes and only a little change of the across-shore component is observed. Given that the maximum wind speeds with the CTWR are in excess of $5 \mathrm{~m} \mathrm{~s}^{-1}$, the event is classified as strong following criteria established by Bond et al. (1996).

\section{Airborne observations of the CTWR}

\section{a. 23 June 2006 (flight 1)}

At 1435 UTC 23 June the UWKA left the base station of Arcata, California, to document atmospheric conditions associated with the CTWR. At that time the CTWR head was situated near Point Arena. A ferry time of approximately $1 \mathrm{~h}$ was required to reach the low-level stratus near the head of the CTWR. As the UWKA approached the CTWR, sawtooth profiles were conducted along the axis of the wind reversal parallel to the coast to capture the vertical structure of the atmosphere adjacent to the reversal. The individual 

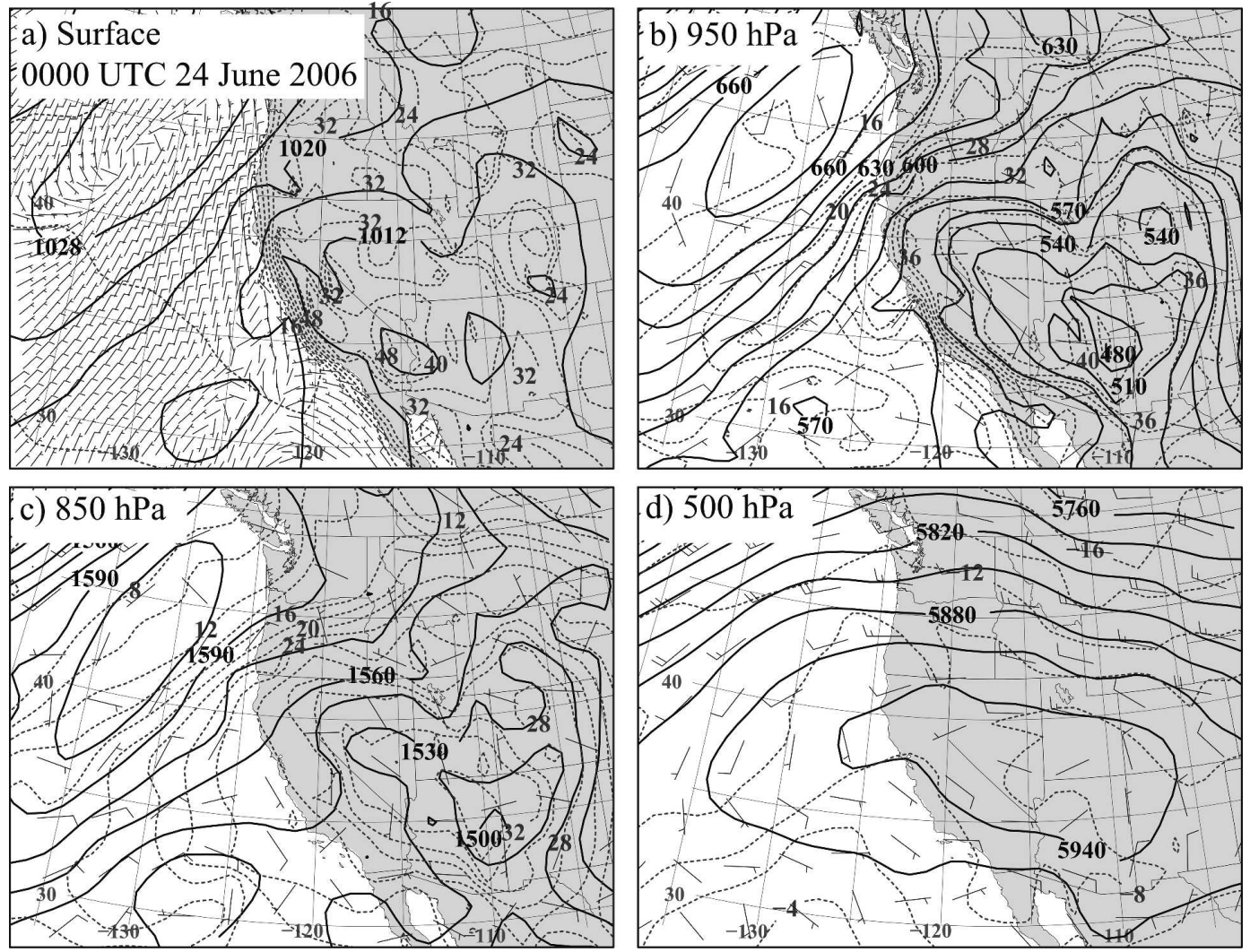

FIG. 6. As in Fig. 3, but for 24 Jun 2006.

sawtooth legs ranged in height between about 150 and $900 \mathrm{~m}$ above the surface of the ocean. To ensure accurate wind sensing, vertical ascent rates were limited to $150 \mathrm{~m} \mathrm{~min}^{-1}$. As a consequence, individual sawtooth profiles were conducted over a horizontal distance of about $30 \mathrm{~km}$. Contouring of variables between observations taken during the sawtooth legs utilize a linear interpolation. For all figures, the horizontal distance along the flight is given in kilometers on the abscissa. This distance is measured from a reference point that is taken as either the northernmost or westernmost point in the particular leg and offset from the origin by $5 \mathrm{~km}$. A distance scale is used since the aircraft position is not along a single latitude or longitude direction, making reporting the location with latitude and longitude cumbersome. For reference, a satellite image with the flight track superimposed is shown for each leg that is discussed.

Figure 9 illustrates the results of the vertical cross sections that have been interpolated from the sawtooth maneuver from 1645 to 1726 UTC. The path of the sawtooth is shown with respect to the position of the stratus signature at the time of the maneuver (Fig. 9a). Point Arena is at roughly the center of the leg with the clouds at the head of the CTWR at approximately 50 $\mathrm{km}$ for the distance scales shown. The structure of the MBL can be seen in the potential temperature field depicted in Fig. 9b. Note that the isentropes slope upward to the south, implying that the CTWR is deeper

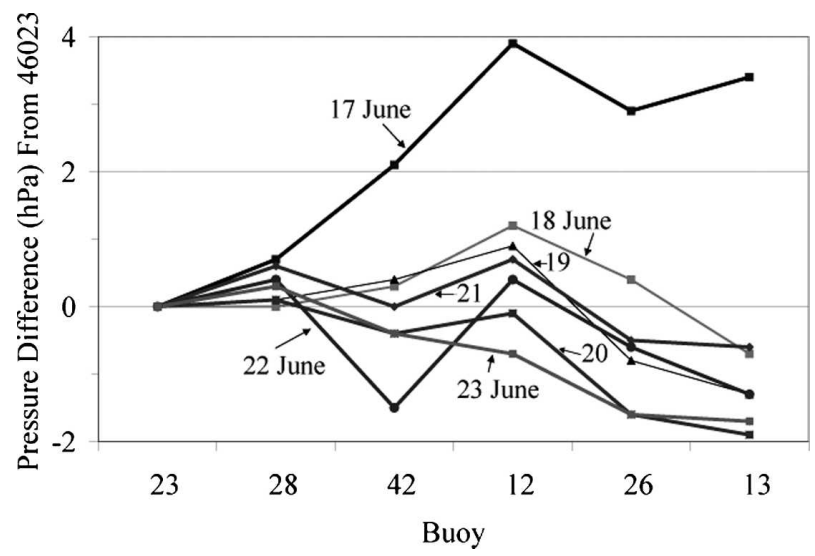

FIG. 7. Pressure difference (hPa) from buoy 46023 at 0000 UTC for buoys along the California coast from 17 to 23 Jun 2006. As in Fig. 1, buoy numbers $\mathrm{xx}$ represent buoys numbered $460 \mathrm{xx}$ by the NDBC. 

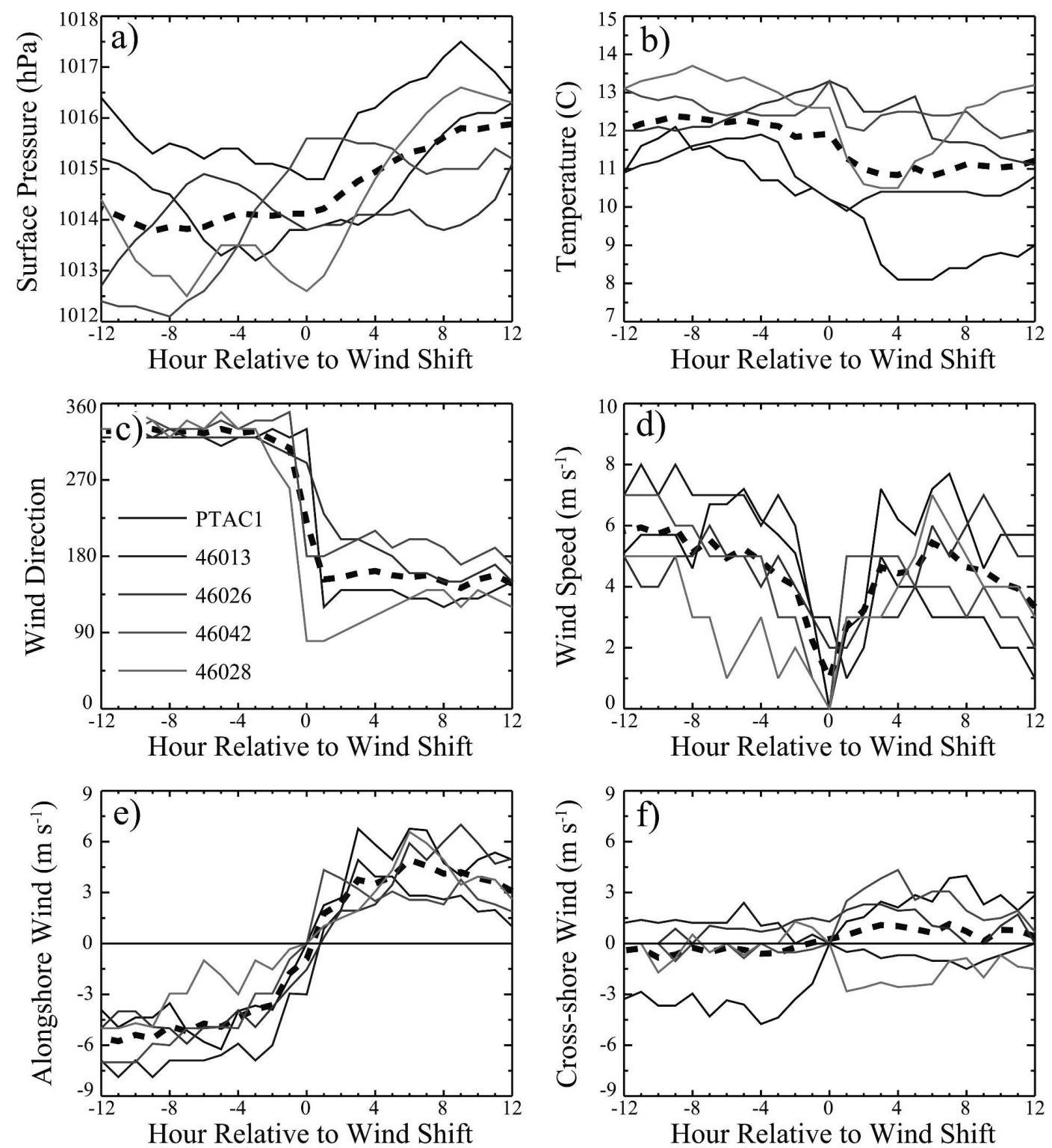

FIG. 8. Time series relative to wind shift of (a) pressure $(\mathrm{hPa}),(\mathrm{b})$ temperature $\left({ }^{\circ} \mathrm{C}\right),(\mathrm{c})$ wind direction $\left({ }^{\circ}\right),(\mathrm{d})$ total wind speed $\left(\mathrm{m} \mathrm{s}^{-1}\right),(\mathrm{e})$ alongshore wind speed $\left(\mathrm{m} \mathrm{s}^{-1}\right)$, and (f) cross-shore wind speed $\left(\mathrm{m} \mathrm{s}^{-1}\right)$ for NDBC buoys 460xx along the California coast and one coastal surface station (PTAC1) during the period of CTWR passage.

and cooler than the ambient environment. This observation differs from those of Ralph et al. (1998) that suggested little change in the depth of the CTWR layer southward from its head. Although the stratus deck is limited to heights below approximately $200 \mathrm{~m}$, the pool of cold air can be seen to extend up to nearly $500 \mathrm{~m}$ near the southern extent of the sawtooth leg. There is a distinct thickening of the MBL from the head of the reversal southward. Winds directed cross-shore and alongshore (as defined above), corresponding to roughly normal and parallel to the flight leg, are shown in Figs. 9c and 9d, respectively. The cross-shore winds are weak with little structure and are directed offshore for the most part, being directed onshore only behind the leading edge of the CTWR that may be associated with flow around Point Arena. Significant gradients exist in the alongshore flow, especially near the head of the CTWR at approximately $50 \mathrm{~km}$ from the start of the sawtooth as shown in Fig. 9d. Maximum alongshore winds are approximately $5 \mathrm{~m} \mathrm{~s}^{-1}$. Note that the zone of southerly flow south of the CTWR head is present throughout the entire vertical extent of the sawtooth 

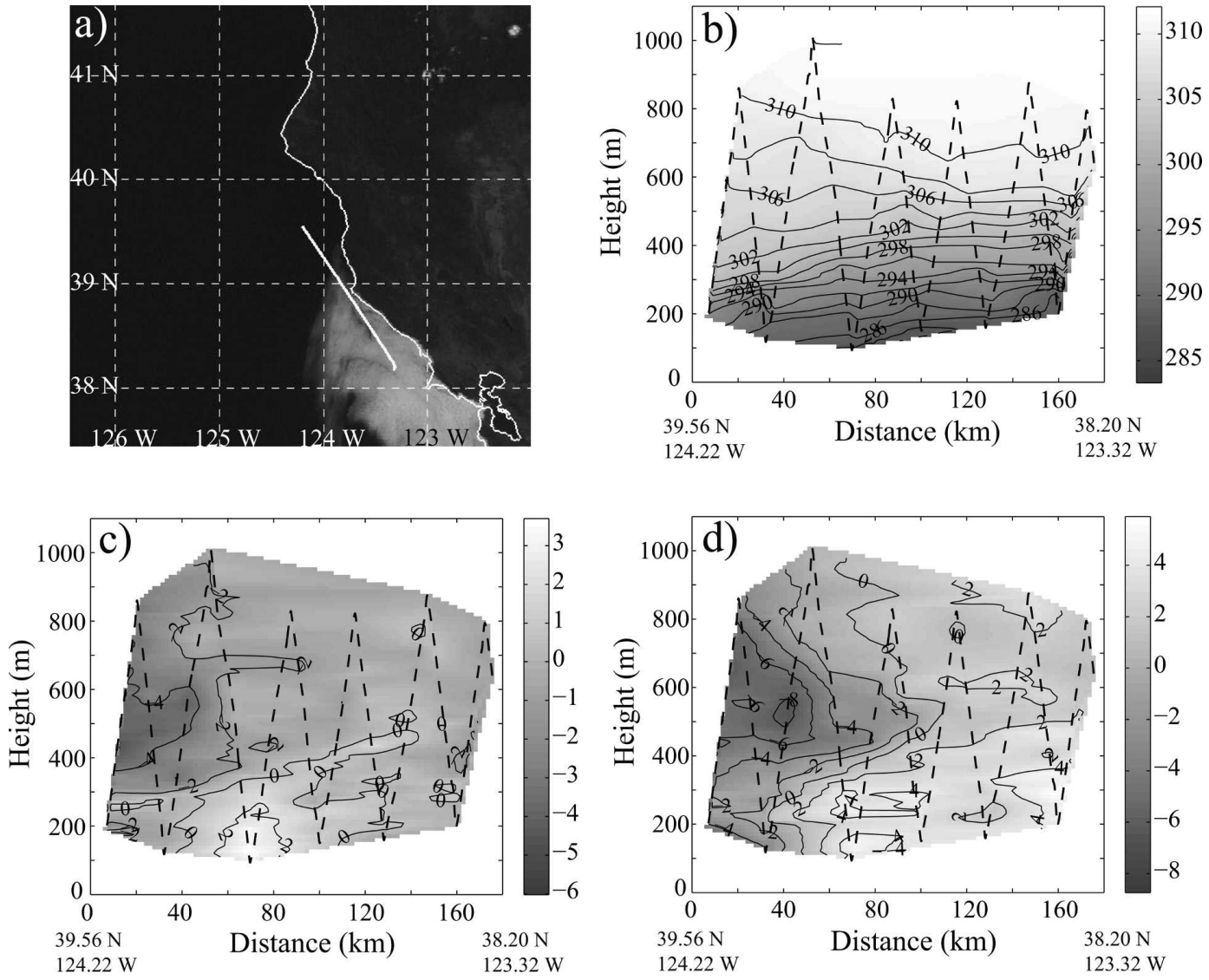

FIG. 9. Sawtooth leg from 1645 to 1726 UTC 23 Jun 2006 showing (a) visible satellite image at 1700 UTC 23 Jun 2006 overlaid with the flight track (solid), (b) potential temperature (solid and shaded grayscale; K), (c) cross-shore wind speed (solid and shaded grayscale; $\mathrm{m} \mathrm{s}^{-1}$ ), and (d) alongshore wind speed (solid and shaded grayscale; $\mathrm{m} \mathrm{s}^{-1}$ ). The flight track is overlaid as a dashed line.

leg. Isotachs display a marked upward slope starting at the head of the CTWR and extending southward, which roughly parallels the trend of the isentropes. North winds in excess of $8 \mathrm{~m} \mathrm{~s}^{-1}$ were observed above the head of the CTWR.

After the first sawtooth profile was completed, the flight strategy was to measure the alongshore horizontal pressure gradient force (PGF) across the leading edge of the CTWR. To measure the PGF, reciprocal flight legs (i.e., repeating flight legs between points along the same path) are conducted at constant pressure using the autopilot between 1728 and 1806 UTC. Since the entire track was over the ocean, the absolute height of an isobaric surface can be determined from the radar altimeter height measurement. Two radar altimeters are present on the UWKA to provide a check as to the fidelity of the measurement of aircraft height above the ocean. Heights obtained from both altimeters as well as those inferred using differential GPS techniques (Parish et al. 2007) are in good agreement.
Results shown here utilize the APN-232 radar altimeter. The slope of an isobaric surface is a measure of the PGF. The small deviations of the aircraft from the selected pressure level can be corrected using the hydrostatic equation. Following Parish (2000), a set of two consecutive low-level isobaric legs $(996 \mathrm{hPa}, \sim 175 \mathrm{~m}$ AGL) were conducted that were oriented in an alongshore direction covering about $80 \mathrm{~km}$ and centered at the cloud edge of the CTWR (Fig. 10a). Corrected isobaric heights from the reciprocal legs are illustrated in Fig. 10b and reveal a slope that is directed downward to the north, implying a PGF directed north. Wavelike features in the isobaric surface are evident at the head of the CTWR on the second leg. The PGF directed along the flight path using data from both legs has a magnitude corresponding to a geostrophic wind of 5 $\mathrm{m} \mathrm{s}^{-1}$ directed onshore, although local isobaric slopes are greater within the CTWR itself. For reference it should be noted that the roughly 4-m height change of the isobaric surface shown in Fig. 10b corresponds to a 

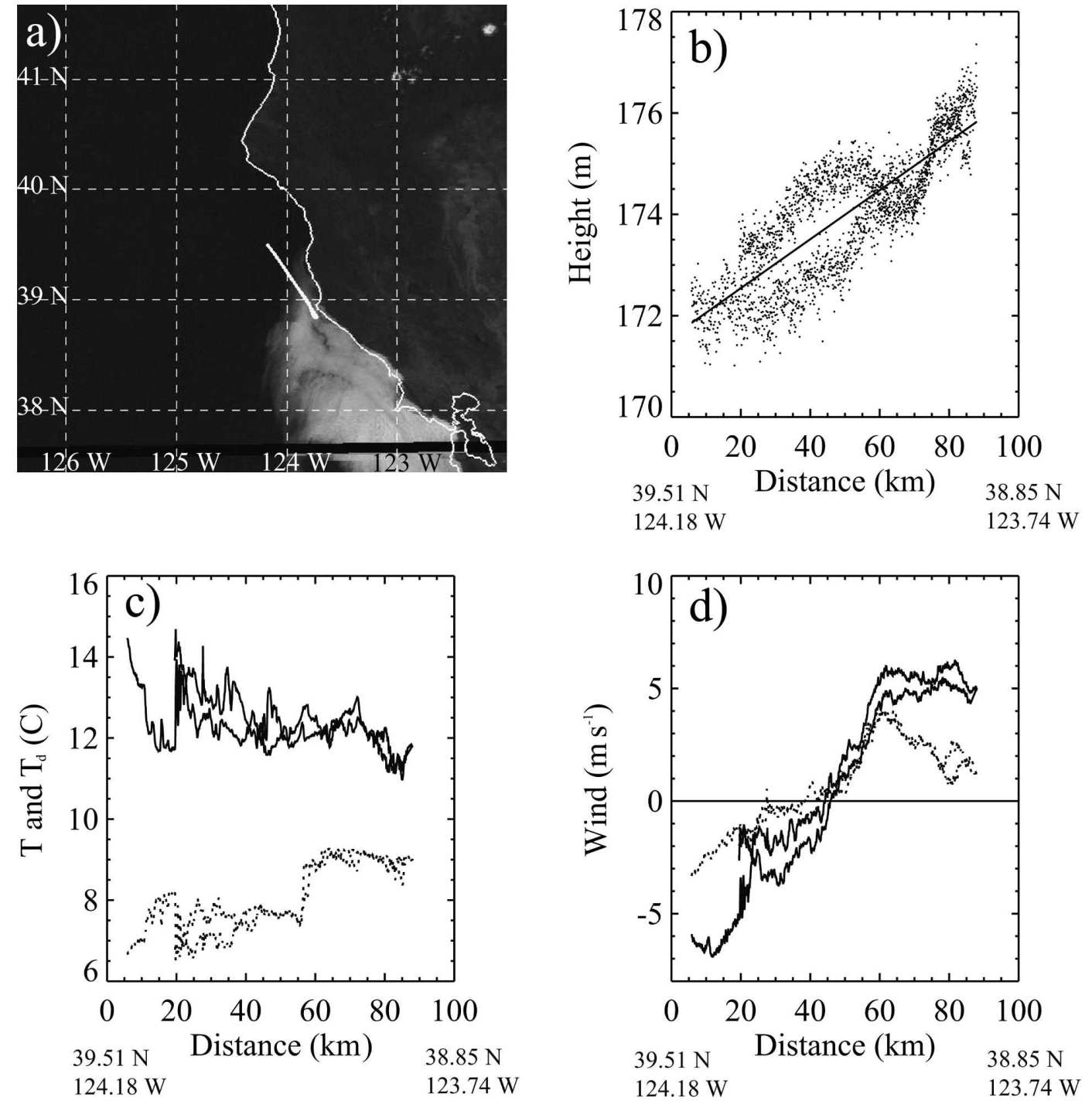

FIG. 10. Isobaric leg at $996 \mathrm{hPa}$ from 1728 to 1806 UTC 23 Jun 2006 showing (a) visible satellite image at 1745 UTC 23 Jun 2006 overlaid with the flight track (solid), (b) height (m) and linear regression line, (c) temperature and dewpoint temperature (solid and dotted, respectively; ${ }^{\circ} \mathrm{C}$ ), and $(\mathrm{d})$ alongshore and cross-shore wind speed (solid and dotted, respectively; $\mathrm{m} \mathrm{s}^{-1}$ ).

horizontal pressure change of approximately $0.45 \mathrm{hPa}$. This is relatively small compared with the changes observed in the large-scale pressure field shown Fig. 8a and is consistent with the pressure signal observed by buoys along the coast in response to the wind shift.

Temperatures along the isobaric leg (Fig. 10c) indicate only a gradual cooling as the plane crosses into the CTWR; the dewpoint temperature trace shows a rapid increase at $35 \mathrm{~km}$ and that this level was above the stratus deck, suggesting that clouds are not present throughout the entire CTWR layer. Figure 10d illustrates the alongshore and cross-shore components of the wind field to show that the alongshore components become positive 5-10 km ahead of the dewpoint temperature signature. Note also that the flow associated with the CTWR contains a significant ageostrophic component. Cross-shore wind components are -3 $\mathrm{m} \mathrm{s}^{-1}$ at the northern end of the leg and increase to about $4 \mathrm{~m} \mathrm{~s}^{-1}$ just behind the head of the CTWR near $60 \mathrm{~km}$ and then decrease to the south within the reversal layer. Alongshore wind components increase monotonically north-south and remain between 5 and 6 $\mathrm{m} \mathrm{s}^{-1}$ within the reversal layer.

To explore the vertical cross section normal to the stratus tongue, a sawtooth flight pattern was conducted between 150 and $800 \mathrm{~m}$ AGL directed toward the west 

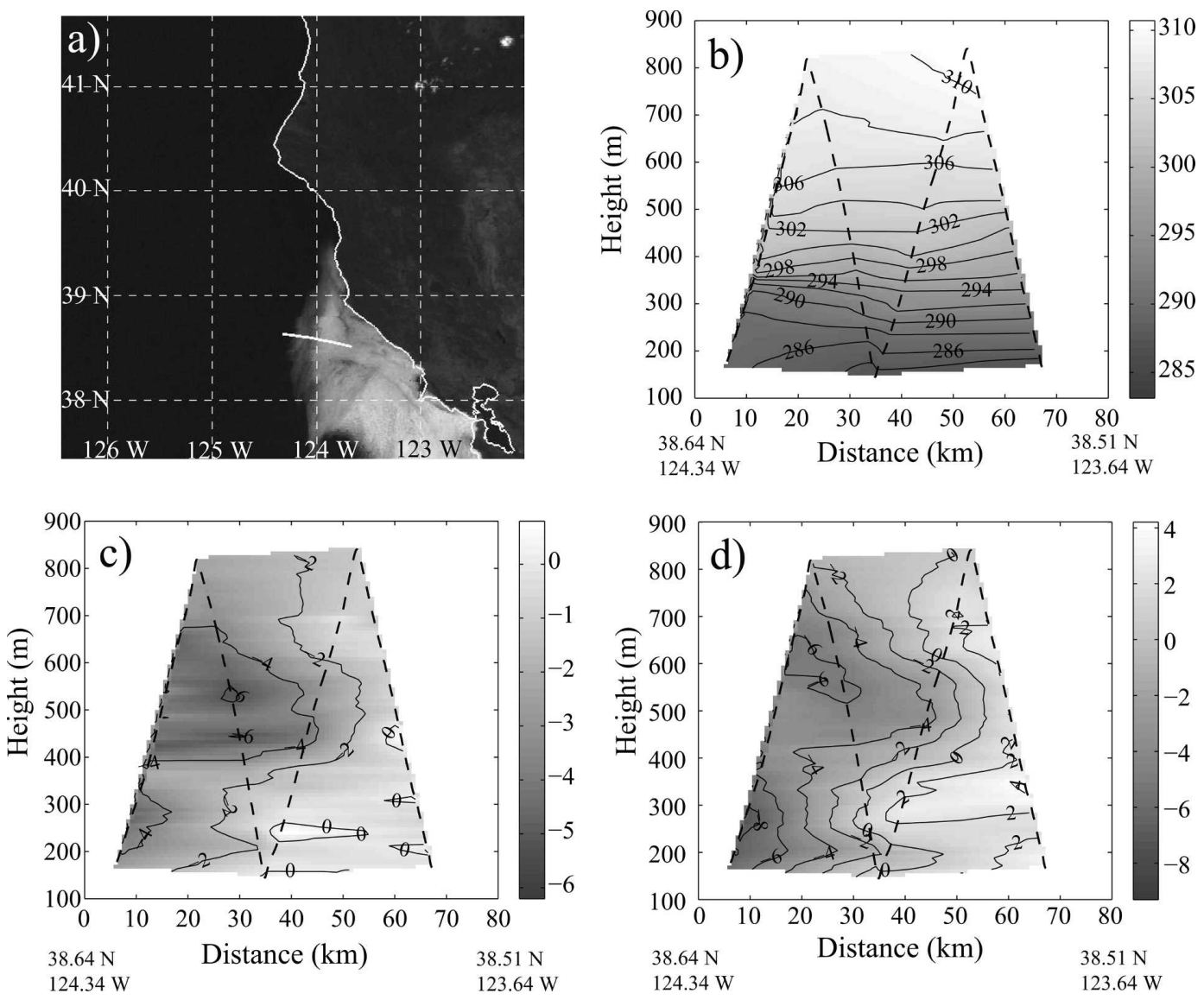

FIG. 11. Sawtooth leg from 1840 to 1854 UTC 23 Jun 2006 showing (a) visible satellite image at 1845 UTC 23 Jun 2006 overlaid with the flight track (solid), (b) potential temperature (solid and shaded grayscale; K), (c) cross-shore wind speed (solid and shaded grayscale; $\mathrm{m} \mathrm{s}^{-1}$ ), and (d) alongshore wind speed (solid and shaded grayscale; 2 $\mathrm{m} \mathrm{s}^{-1}$ ). The flight track is overlaid as a dashed line.

from 1840 to 1854 UTC. Figure 11a illustrates the horizontal track of the sawtooth leg with respect to the stratus clouds. From the cross section of potential temperature (Fig. 11b) a strong inversion at the top of the MBL at about $350 \mathrm{~m}$ AGL in the west can be seen. Toward the east and within the CTWR, isentropes tend to be more evenly spaced. There is some sloping of the isentropes down from the west end to the central region of the leg, suggesting a pressure gradient directed to the east. In the eastern region isentropic surfaces are oriented in a horizontal direction, suggesting that the horizontal temperature gradient within the CTWR layer is near zero. This differs somewhat from data obtained by aircraft for the 11 June 1994 CTWR by Ralph et al. (1998), which suggests that isentropes slope slightly upward toward the east. There is no obvious evidence of strong changes in the MBL height or structure within the CTWR in the east. The cross-shore wind speeds (Fig. 11c) only reach $2 \mathrm{~m} \mathrm{~s}^{-1}$ within the CTWR, but there is a significant offshore component aloft and west of the CTWR. The southerly wind within the CTWR (Fig. 11d) is also weak with magnitudes approaching $3 \mathrm{~m} \mathrm{~s}^{-1}$. A north wind near $8 \mathrm{~m} \mathrm{~s}^{-1}$ is observed at the west end of the leg.

To examine the cross-shore PGF, a low-level isobaric leg was conducted orthogonal to the western edge of the CTWR stratus (Fig. 12a) at a pressure level of 996 $\mathrm{hPa}(\sim 175 \mathrm{~m}$ AGL) between 1855 and 1914 UTC. Corrected isobaric heights are shown in Fig. 12b, and show two distinct regions that correspond to inside and outside of the CTWR. West of the CTWR, the MBL slopes downward to the east with a PGF that is directed to the east. This is consistent from climatology with higher pressure to the west associated with the Pacific high. The associated geostrophic wind component here is 11 $\mathrm{m} \mathrm{s}^{-1}$ from the north. Within the CTWR in the east, the pressure gradient is quite weak, yielding no substantial geostrophic wind components in a direction normal to the flight track. Although the flight leg terminates about $20 \mathrm{~km}$ from the coast, no detectable increase in 

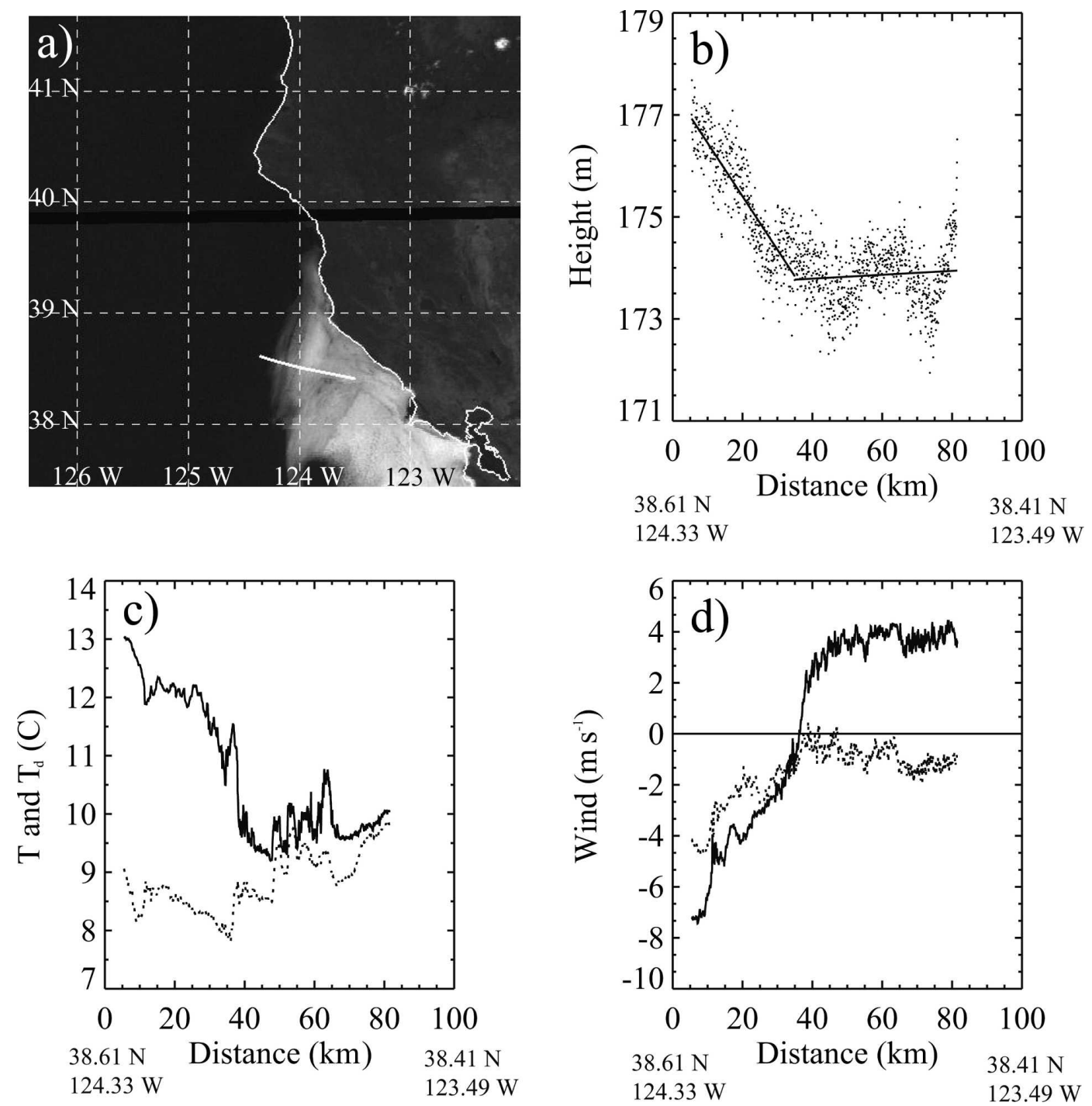

FIG. 12. Isobaric leg at $998 \mathrm{hPa}$ from 1855 to 1914 UTC 23 Jun 2006 showing (a) visible satellite image at 1915 UTC 23 Jun 2006 overlaid with the flight track (solid), (b) height (m) and linear regression line, (c) temperature and dewpoint temperature (solid and dotted, respectively; ${ }^{\circ} \mathrm{C}$ ), and (d) alongshore and cross-shore wind speed ( solid and dotted, respectively; $\mathrm{m} \mathrm{s}^{-1}$ ).

either the MBL thickness or pressure was encountered. The lack of a cross-shore PGF observed during this leg is consistent with the potential temperature cross sections discussed above as well as observations conducted later on in the day (to be discussed later). The weak cross-shore PGF is an important difference between the observations conducted during this CTWR and those inferred from the 10-11 June 1994 CTWR. Ralph et al. (1998) suggested that a mesoscale high pressure regime near the coast was present for the 1994 case. Pressure differences such as those implied by the analyses shown in Figs. 7 and 11 in Ralph et al. (1998) would be easily detectable from data collected during the isobaric flight legs; corresponding height changes for even a 1-hPa signal would be nearly $10 \mathrm{~m}$.

Temperature and dewpoint temperature (Fig. 12c) clearly show cooler temperatures and more moist conditions within the CTWR. This isobaric leg was conducted near the top of the stratus and the UWKA was in and out of the stratus deck as it moved across the CTWR. Cross-shore and alongshore wind components show the edge of the CTWR to be at a distance of 35 $\mathrm{km}$ in Fig. 12d. Winds are uniform for the $40-\mathrm{km}$ distance within the CTWR. Note that the wind rapidly returns to strong northerly flow within $30 \mathrm{~km}$ of the reversal. 

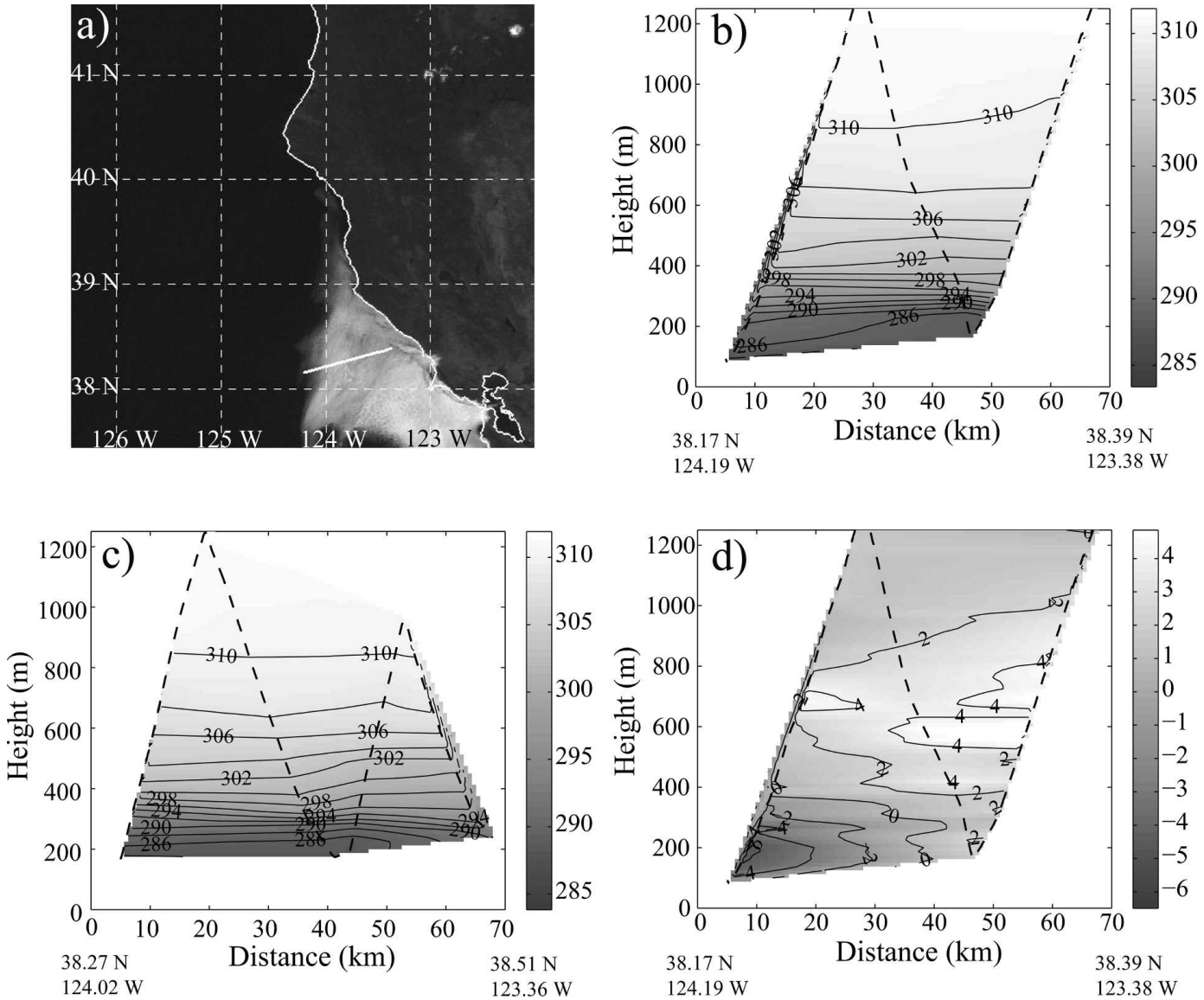

FIG. 13. Sawtooth leg from 2103 to 2118 UTC 23 Jun 2006 showing (a) visible satellite image at 2130 UTC 23 Jun 2006 overlaid with the flight track (solid), (b) potential temperature (solid and shaded grayscale; K), (c) return flight (2129-2143 UTC) potential temperature (solid and shaded grayscale; K), and (d) original alongshore wind speed (solid and shaded grayscale; $2 \mathrm{~m} \mathrm{~s}^{-1}$ ). The flight track is overlaid as a dashed line.

\section{b. 23 June 2006 (flight 2)}

After refueling at Santa Rosa, the UWKA embarked on the second CTWR flight at 2040 UTC 23 June. Results from three flight strategies will be presented from the afternoon flight: cross-shore sawtooth legs through the CTWR, low-level isobaric legs orientated in alongshore and cross-shore directions across the CTWR, and a long sawtooth leg orientated along the coast from south to north designed to show the transition from the CTWR environment to the typical north wind regime found near Cape Mendocino.

Two sawtooth legs in the cross-shore direction were conducted between 2103 and 2118 UTC. The first sawtooth is about $60 \mathrm{~km}$ in length, beginning within $15 \mathrm{~km}$ of the coast and heading west (Fig. 13a). From the cross section of potential temperature (Fig. 13b), a strong inversion is present at the top of the MBL in the east at about $350 \mathrm{~m}$ AGL. Isentropes slope downward toward the west, a feature also observed by Ralph et al. (1998).
A return sawtooth leg was also conducted from 2129 to 2143 UTC that terminated within $10 \mathrm{~km}$ of the coastline in attempt to detect possible blocking or trapping of the flow, mechanisms that have been suggested as potentially relevant to CTWR propagation (e.g., Nuss et al. 2000). Figure 13c illustrates the isentropic cross section from that segment, which shows little evidence of significant blocking or cold air pooling adjacent to the coastal range at this time. It appears as though the coldest air is in place about $20 \mathrm{~km}$ from the eastern end of the sawtooth. Isentropes show only a gradual upward slope toward the east, similar to the east-west sawtooth conducted in the morning (Fig. 11b) and again suggest that no significant cross-shore PGF exits. Cross-shore winds (not shown) are light and show little difference from that displayed previously. Alongshore winds (Fig. 13d) are also consistent with observations from earlier in the day with south winds extending well above the cloud layer, which was found in the lowest $175 \mathrm{~m}$ above the ocean. Maximum southerly winds in excess of 4 

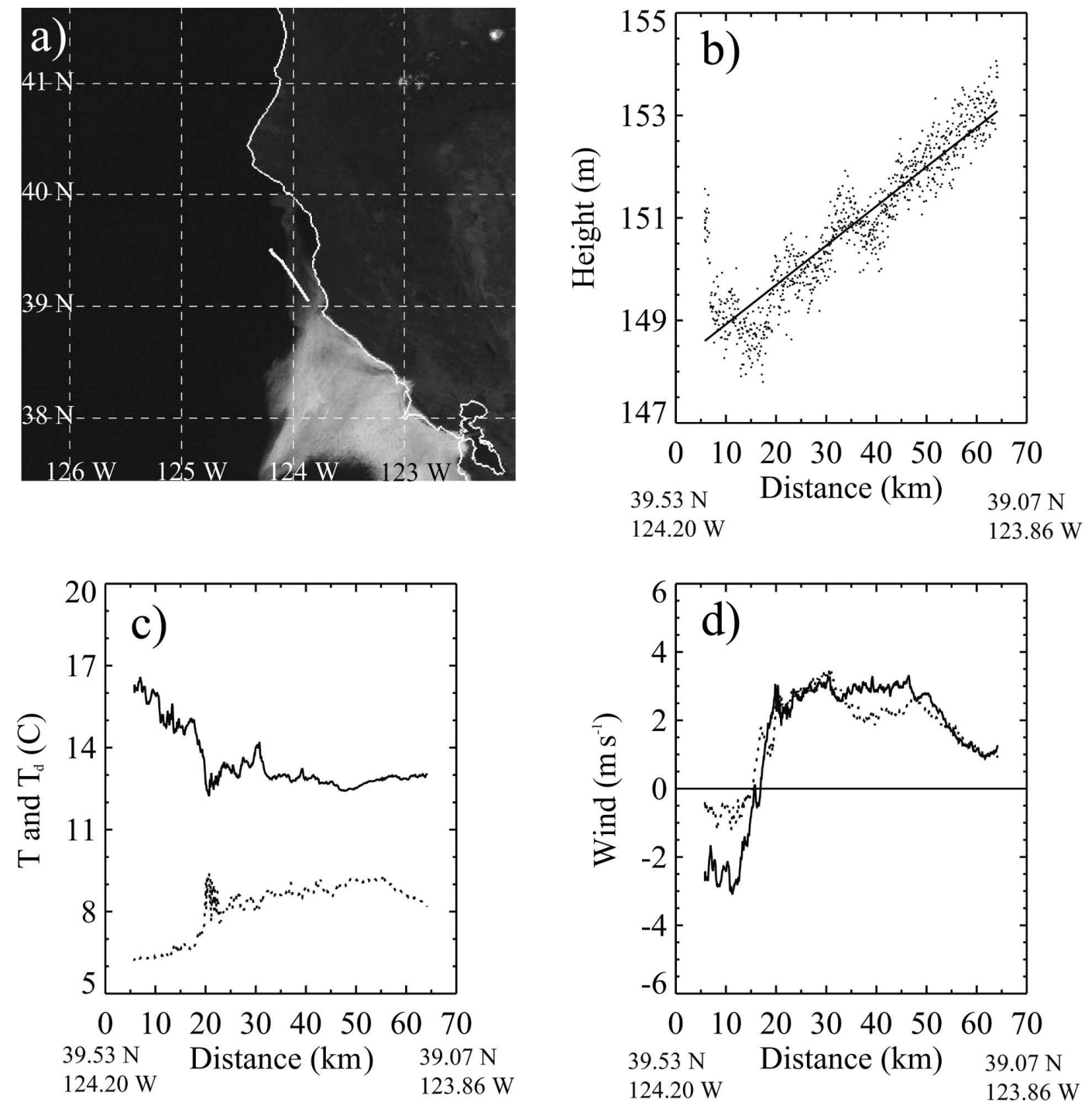

FIG. 14. Isobaric leg at $998 \mathrm{hPa}$ from 2238 to 2253 UTC 23 Jun 2006 showing (a) visible satellite image at 2245 UTC 23 Jun 2006 overlaid with the flight track (solid), (b) height (m) and linear regression line, (c) temperature and dewpoint temperature (solid and dotted, respectively; ${ }^{\circ} \mathrm{C}$ ), and (d) alongshore and cross-shore wind speed (solid and dotted, respectively; $\mathrm{m} \mathrm{s}^{-1}$ ).

$\mathrm{m} \mathrm{s}^{-1}$ were observed at a height of about $550 \mathrm{~m}$, well above the MBL. North winds with a jet profile were observed along the western edge of the sawtooth leg just past the stratus deck.

After the sawtooth legs, the UWKA was situated at $38.5^{\circ} \mathrm{N}, 123.3^{\circ} \mathrm{W}$, southeast of the CTWR head. Reciprocal isobaric legs at $160 \mathrm{~m}$ above the ocean surface were then conducted in a direction roughly perpendicular to the coastline in attempt to detect the cross-shore PGF. Each leg was approximately $35 \mathrm{~km}$ in length, mostly within the CTWR layer and reaching within 10 $\mathrm{km}$ of the coast. As seen with the cross-shore legs in the earlier flight, no significant PGF was seen in either leg and hence the results are not shown. These isobaric surface slopes suggest that blocking by the coastal terrain was not a dynamically significant factor at this location within the CTWR layer. Following the second cross-shore leg, the flight strategy was to focus again on the alongshore conditions. An isobaric leg approximately $150 \mathrm{~m}$ AGL was conducted to measure the alongshore PGF from 2238 to 2253 UTC. Each leg was directed through the head of the CTWR (Fig. 14a). Unlike the case seen in the cross-shore isobaric legs, the alongshore isobaric leg showed clear evidence of the northward-directed PGF. The measured isobaric surface (Fig. 14b) has a pressure gradient force directed to 

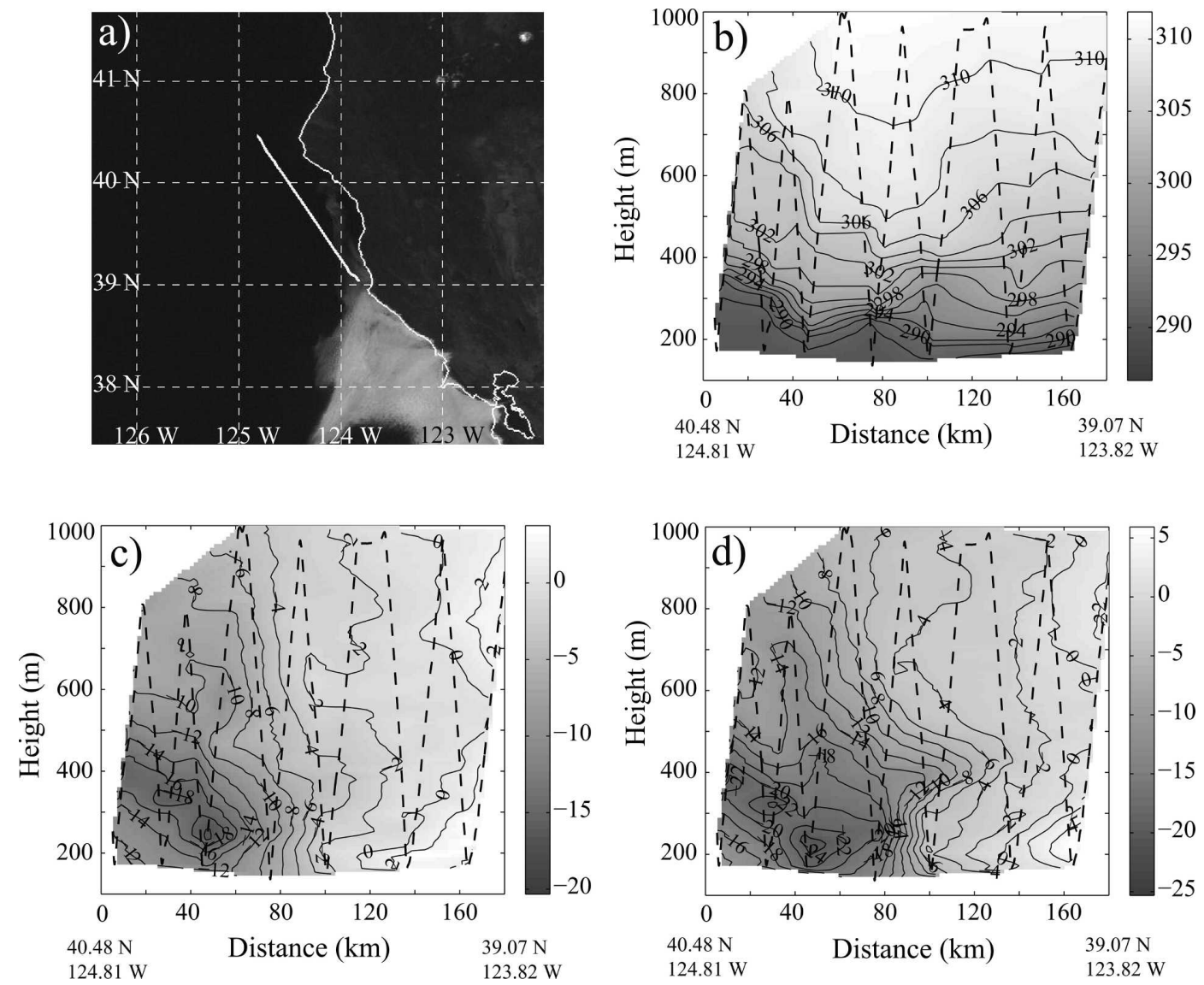

FIG. 15. Sawtooth leg from 2256 to 2339 UTC 23 Jun 2006 showing (a) visible satellite image at 2315 UTC 23 Jun 2006 overlaid with the flight track (solid), (b) potential temperature (solid and shaded grayscale; K), (c) cross-shore wind speed (solid and shaded grayscale; $\mathrm{m} \mathrm{s}^{-1}$ ), and (d) alongshore wind speed (solid and shaded grayscale; 2 $\mathrm{m} \mathrm{s}^{-1}$ ). The flight track is overlaid as a dashed line.

the north, and there is some evidence of a rapid increase in height at the extreme northern end of the leg that represents the adverse pressure gradient ahead of the CTWR. The PGF along the leg has a magnitude equivalent to an $8 \mathrm{~m} \mathrm{~s}^{-1}$ geostrophic wind. Temperatures along the leg reveal that the air associated with the CTWR was about $3 \mathrm{~K}$ cooler than that found to the north, indicating that the reversal was of higher density than the ambient environment. There is a decrease of temperature (Fig. 14c) from the north end until the wind shift. The wind components are generally light $\left(<3 \mathrm{~m} \mathrm{~s}^{-1}\right)$ for the entire leg. There is a south wind of about $3 \mathrm{~m} \mathrm{~s}^{-1}$ within the CTWR. Once again a sharp gradient is seen at the north end of the leg where the wind is a $2 \mathrm{~m} \mathrm{~s}^{-1}$ wind from the north. To the north ahead of the CTWR, the wind is weakly onshore. Within the CTWR the wind is directed onshore at about $3 \mathrm{~m} \mathrm{~s}^{-1}$.

After completion of the isobaric legs, the UWKA was positioned to the southeast of the CTWR head.
The final leg of this flight was an alongshore sawtooth leg that passed through the head of the CTWR and extended $150 \mathrm{~km}$ north of the reversal (Fig. 15a). Cross sections of the data collected during this leg illustrate striking changes in both wind and temperature as the plane moves from the CTWR layer to the climatologically prevalent north wind regime. It can be seen that the topology of the MBL changes significantly along the coast as evidenced by the vertical structure of the potential temperature field (Fig. 15b). This sawtooth leg commenced near the head of the CTWR (at about $140 \mathrm{~km}$ in Fig. 15b) and isentropic surfaces slope up toward the south within the CTWR. To the north of the reversal layer, isentropic surfaces show a dramatic separation (near the $90-\mathrm{km}$ distance), suggesting convergence and dynamic destabilization within the lowest $400 \mathrm{~m}$. Farther north the MBL takes on climatological characteristics with isentropes sloping upward to the north, suggesting that a cold pool of air resides over the ocean in association with the northerly jet. The depth of 
the MBL lowers from about $400 \mathrm{~m}$ to about $250 \mathrm{~m}$ over a horizontal distance of only $40 \mathrm{~km}$. There is some evidence that this sudden lowering may reflect dynamical interaction with Cape Mendocino. The top of the MBL appears to be much more stable to the north in general. The CTWR layer is characterized as having an MBL that is not as clearly defined as that associated with the northerly flow. This result may support the conclusion that a two-layer model cannot adequately represent the MBL associated with the CTWR layer, as suggested by Ralph et al. (1998).

Cross-shore wind components within the CTWR are again weak and diffuse (Fig. 15c) but become better organized to the north where northeast winds are found having a jet profile. A highly coherent structure is seen in the alongshore wind components (Fig. 15d). The abrupt change in the MBL thickness is tied in part to the alongshore winds. Wind speeds change rapidly with distance, especially between the 80 and $100 \mathrm{~km}$ distances where alongshore components change from 6 to $20 \mathrm{~m} \mathrm{~s}^{-1}$. Strong convergence along the flight path occurs here that is most likely not compensated by across flight components, which is consistent with the dynamic destabilization represented in the potential temperature surfaces over this same distance. It is not surprising that the isentropic cross section to the south of the CTWR does not display a sharp inversion given the strong convergence. Note the secondary stable layer below this destabilized region that appears to be created from the spreading aloft. This may be important when examining the cloud from radar products.

\section{Characteristics and structure of the stratus layer}

While the appearance and northward propagation of a low-level stratus layer is one of the characteristic features of a CTWR, little is known about the characteristics of the cloud layer and the role played by the cloud layer in the propagation and maintenance of the event-one of the few numerical simulations in which the role of clouds was considered was described by Thompson et al. (2005).

The stratus layer accompanying the CTWR on 23 June 2006 was extremely shallow with cloud-top height increasing from just above the surface to $\sim 200 \mathrm{~m}$ at the southern and eastern ends of the legs (Fig. 16). The shallowness of the stratus layer, which occupied only the lowest one-third to one-half of the CTWR layer with maximum cloud-top heights of less than $225 \mathrm{~m}$, prevented the UWKA from flying within the cloud layer for an extended period except for a single isobaric leg during the first flight on 23 June (between 1855:30 and 1914:20 UTC). The aircraft also dipped into cloud at the bottom of the sawtooth patterns on a handful of legs from both flights on 23 June. The limited in situ cloud microphysics measurements from the penetrations into cloud are supplemented by observations from the Wyoming Cloud Radar (WCR), a 95-GHz Doppler radar designed for studies of clouds and precipitation. The WCR configuration onboard the UWKA includes a pair of downward-looking beams that allow radar reflectivity and Doppler velocity to be obtained from 100 $\mathrm{m}$ below the aircraft to within approximately $30 \mathrm{~m}$ of the surface (given the 225-ns pulse length used during the flight). [Additional information regarding the WCR and its configuration on board the UWKA can be found in Leon et al. (2006) and online at http://wwwdas.uwyo.edu/wcr/.]

Most of the in situ cloud microphysics data on 23 June was obtained on the $996 \mathrm{hPa}$ ( 175-m altitude), cross-shore leg flown between 1855:30 and 1914:20 UTC. The aircraft was predominantly in cloud from the 37.5 - to $52.5-\mathrm{km}$ distance, intermittently in cloud between the 52.5 - and $65-\mathrm{km}$ distance, and continuously in cloud from $65 \mathrm{~km}$ to the end of the leg at $80+\mathrm{km}$. These segments can be seen to correspond, respectively, to a band of brighter cloud, a reduced albedo region, followed by a higher albedo region in the Geostationary Operational Environmental Satellite (GOES) visible satellite image shown in Fig. 12a. Peak cloud liquid water content (LWC) measured using the Droplet Measurement Technologies (DMT) LWC-100 probe reached $0.45 \mathrm{~g} \mathrm{~m}^{-3}$ in the segment between 37.5 and $52.5 \mathrm{~km}$ and between 0.40 and $0.45 \mathrm{~g} \mathrm{~m}^{-3}$ in the segment from $65 \mathrm{~km}$ to the end of the leg. LWCs obtained from the Gerber PVM-100 and the Particle Measuring Systems (PMS) Forward Scattering Spectrometer Probe (FSSP-100) were 18\% lower and 9\% higher, respectively, than those from the DMT LWC-100 with an excellent correlation between the three different measurements. Peak LWC values are comparable to, or slightly in excess of, the $0.40 \mathrm{~g} \mathrm{~m}^{-3}$ that would be expected for an adiabatic cloud layer with the observed cloud-top temperature and cloud base at the ocean surface-effectively confirming that the stratus layer extends to the ocean surface. The observed LWC is significantly less than the peak values of $\sim 1 \mathrm{~g} \mathrm{~m}^{-3}$ reported by Thompson et al. (2005). Cloud-droplet number concentrations range between 100 and 200 $\mathrm{cm}^{-3}$ for the cloud segment from the $65-\mathrm{km}$ distance to the southeastern end of the leg. Markedly higher droplet concentrations ranging up to $300 \mathrm{~cm}^{-3}$ are found for the northwestern portion of the first in-cloud segment (between the 37.5- and 45.0-km distance). These values, particularly for the southeastern in-cloud segment are 

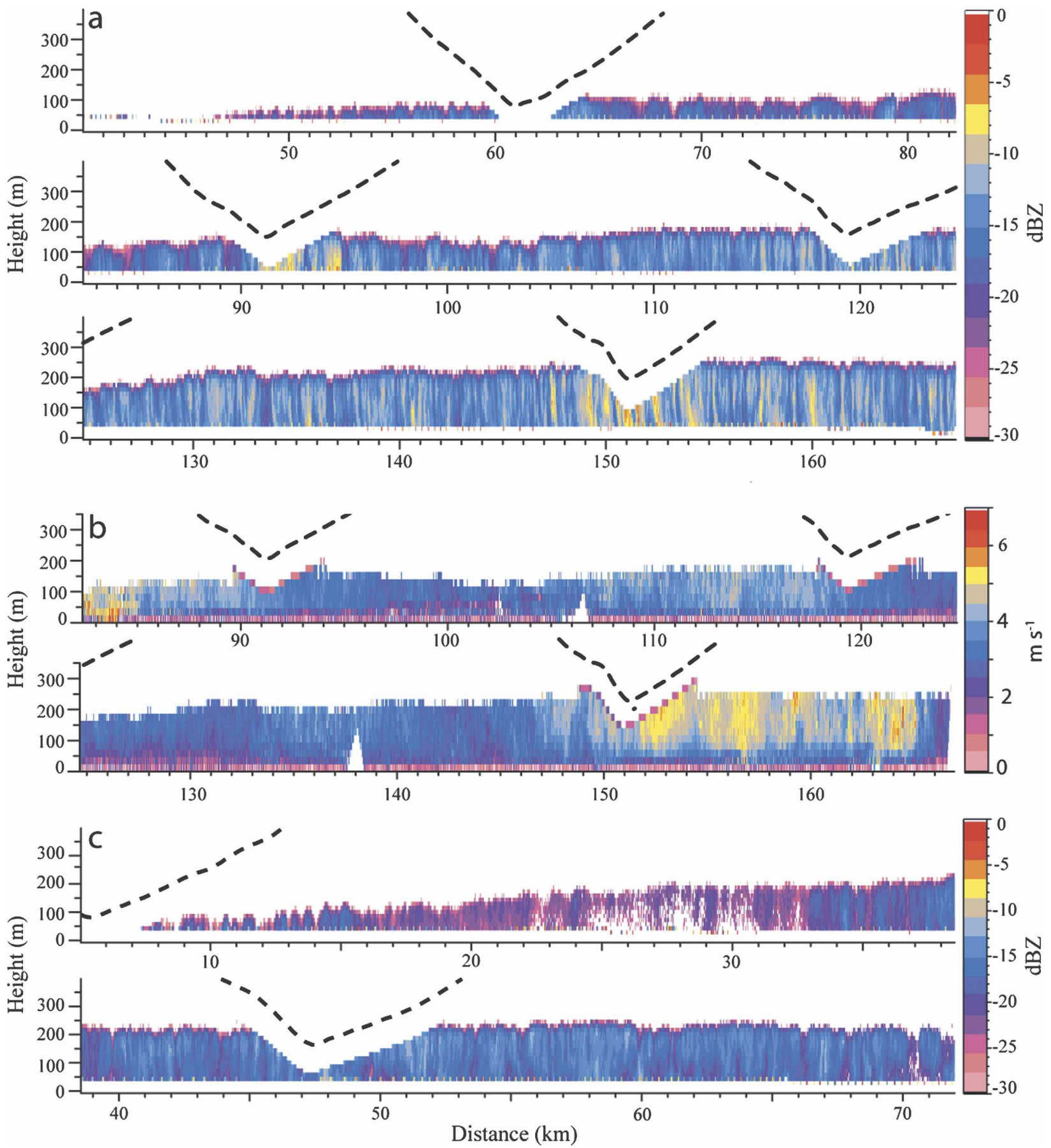

FIG. 16. WCR depictions of (a) reflectivity ( $\mathrm{dBZ}$ ), (b) wind speed cross section $\left(\mathrm{m} \mathrm{s}^{-1}\right)$ from the WCR from the alongshore sawtooth leg 1645:30-1726:20 UTC 23 Jun 2006, and (c) reflectivity (dBZ) from the cross-shore sawtooth leg 2103:00-2118:35 UTC 23 Jun 2006. Positive alongshore velocities indicate motion from right to left in the figures. Cross sections correspond to the legs shown in Figs. 9 and 13, respectively, and use the same definition of distance. The aircraft track is indicated by the dashed black line. Notches in the reflectivity cross section are the result of the $\sim 125$-m dead zone of the WCR impinging onto the cloud layer.

within the range of values previously reported for marine stratocumulus (e.g., vanZanten et al. 2005).

Despite the shallowness of the stratus layer, the radar reflectivity significantly exceeds the detection threshold of the WCR $(<-30 \mathrm{~dB} Z$ at a range of $500 \mathrm{~m})$. Cross sections of radar reflectivity and the leg-parallel velocity component for the alongshore leg depicted in Fig. 9a are shown in Figs. 16a,b, respectively. Reflectivity and 
cloud-top height increase from the leading and lateral boundaries of the CTWR toward the south and east, respectively. The mean radar reflectivity (averaged vertically through the cloud layer) increases from approximately $-25 \mathrm{dBZ}$ at the $50-\mathrm{km}$ distance on the northern end of the alongshore leg to $-13 \mathrm{dBZ}$ at the southern end. The radar reflectivity cross section from the crossshore leg (Fig. 16c) shows a region of weak reflectivity between the 15 - and $35-\mathrm{km}$ distance where the mean reflectivity is $\sim-23 \mathrm{~dB} Z$, even though the cloud-top heights continue to increase across this region. The vertically averaged mean reflectivity reaches $-15 \mathrm{~dB} Z$ by the $40-\mathrm{km}$ distance, near the southeastern end of the weak-reflectivity region, and remains approximately constant between the $40-$ and $70-\mathrm{km}$ distance. Cloudtop height increases gradually from north to south on the alongshore legs rising from just above the surface at the $40-\mathrm{km}$ distance to $\sim 200 \mathrm{~m}$ at the $155-\mathrm{km}$ distance where it levels out. In contrast, the increase in cloudtop height across the lateral boundary of the CTWR is more abrupt rising from just above the surface at the $5-\mathrm{km}$ distance and leveling off at $\sim 200 \mathrm{~m}$ at the $40-\mathrm{km}$ distance.

Both the radar reflectivity values and the structure of the reflectivity field are indicative of drizzle. The radar reflectivity field consists of small cells, which appear as vertical stripes in Fig. 16 owing to the large vertical exaggeration employed in the figure. The cellular structure of the radar reflectivity field, in contrast to a monotonic increase in reflectivity with height that would be expected if cloud droplets dominate the radar reflectivity, suggests that drizzle is present and that it dominates the radar reflectivity. It is likely that the removal of condensed water by drizzle counteracts the production of condensate due to radiative cooling, and offers an explanation for the disparity between the observed LWC of $\sim 0.4 \mathrm{~g} \mathrm{~m}^{-3}$ and the $\sim 1 \mathrm{~g} \mathrm{~m}^{-3}$ in the Thompson et al. (2005) simulation, which did not include drizzle.

The alongshore wind component derived from the WCR Doppler velocities (Leon et al. 2006) from the 1645-1726 UTC sawtooth leg is shown in Fig. 16b. Only minimal vertical shear within the cloud layer is evident in this component. WCR-derived alongshore winds within the stratus layer are southerly at speeds ranging from 3 to $5 \mathrm{~m} \mathrm{~s}^{-1}$ and are in very good agreement in the locations where the aircraft dipped into the cloud layer. While there is little discernible vertical structure in the alongshore wind component, a pattern of convergence/ divergence is evident with the winds decreasing from 5 $\mathrm{m} \mathrm{s}^{-1}$ at the southeastern end of the leg to $\sim 3.5 \mathrm{~m} \mathrm{~s}^{-1}$ before increasing to $5 \mathrm{~m} \mathrm{~s}^{-1}$ at $90 \mathrm{~km}$.

\section{Summary}

Typical synoptic conditions as described in Mass and Bond (1996) and Nuss (2007) are prevalent during this event, including upper-level ridging with the associated surface high moving into the northwestern United States. Offshore flow develops and warms the coastal regions through both advection of warm continental air and also subsidence off the elevated topography, which extends the thermal trough from the desert southwest to out over the ocean west of Los Angeles weakening the alongshore pressure gradient south of Cape Mendocino. The two aircraft flights on 23 June 2006 depict an actively propagating, strong CTWR that is in a mature stage. Satellite imagery near the time of the flights shows a finger of stratus adjacent to the coast and also suggests a mesoscale cyclonic circulation to the west of Monterey Bay.

Observations made during the UWKA vertical sawtooth profiling maneuvers show that the MBL heights vary in relation to the CTWR environment. The first alongshore sawtooth leg ( 1700 UTC) shows an MBL that deepens to the south, farther into the CTWR. This MBL depth is one of the critical measurements as discussed in Nuss et al. (2000). The last extended alongshore sawtooth leg, which began near the cloud edge at the head of the CTWR, and flown to the north depicts a sharp transition from the CTWR environment to the typical north wind regime. The MBL is strongly capped and relatively deep to the north and becomes shallow near Shelter Cove. The strong inversion is destabilized near the middle of the leg most likely because of convergent flow in response to the strong convergence in the alongshore direction that is unlikely balanced by the across-flight divergence. Evidence of enhanced stability near the surface from the upper-level convergence in this last leg may work in conjunction with radiational cooling effects at the top of the cloud layer to suppress cloud-top heights from reaching higher altitudes. The cloud-top heights derived from the WCR reflectivities are quite low. The clouds transition gradually from a thin shallow layer at the CTWR head and western edge to a deeper $(\sim 250 \mathrm{~m})$ cloud well within the CTWR. There is a much steeper gradient of cloudtop heights cross-shore than alongshore. Little, if any, vertical wind shear within the cloud layer is evident in the reflectivity structure observed by the WCR or in the retrieved horizontal velocities. Cloud extent does not match with the other key variables that define the CTWR, emphasizing that the clouds are not a good indicator of CTWR boundaries. Both sawtooth legs suggest a deeper pool of cool air is associated with the CTWR region. 
Isobaric and sawtooth cross-shore legs indicate the lack of a significant PGF directed normal to the coast at the time of these flights. The absence of a cross-coast forcing mechanism is one of the key differences from this CTWR as compared with previous events such as shown in Ralph et al. (1998). Cross-shore sawtooth legs also show some variability. The northerly low-level jet is encountered in the far west portion of the two legs, but at different heights, which correspond to the different locations of the inversion. Clear evidence of damming against the topography is not seen. The strongest capping inversion does not seem to be in one location. The variability of the observed MBL, both inversion strength and location, must be considered to explain the CTWR propagation (Nuss et al. 2000).

The isobaric legs directly measure the PGF as well as key state variables. There is a general decrease of temperature into the CTWR and cooler MBL. When penetrating into the CTWR layer from the west, a distinct discontinuity of the isobaric surface is encountered signifying the transition from the climatologically favored northerly wind regime to the CTWR region. A sharp transition of wind direction between regions is generally well observed. The PGF is directed south-north within the CTWR and north-south outside of the CTWR. The cross-shore PGF is weak within the CTWR. Isobaric surfaces are generally linear within the CTWR with some evidence of wavelike perturbations. Winds are fairly ageostrophic within the CTD, indicating significant acceleration.

This paper presents some of the key observations taken on 23 June 2006 by the UWKA during a strong, mature CTD event, and it depicts the highly variable nature of the MBL. A detailed discussion of the forcing mechanisms for this case will be presented later. Additional aircraft observations were taken over the next 2 days as the CTWR stalls at Cape Mendocino and finally decays as the northerly flow reestablishes itself along the coast.

Acknowledgments. This research was supported in part by the Office of Naval Research through Grant N000140510720 and the National Science Foundation through Grant ATM-0332202. The authors thank pilots Don Cooksey and Kevin Fagerstrom and scientists Jeff Snider and Jeff French for help with the field measurements.

\section{REFERENCES}

Bane, J. M., 1997: Airflow and stratification in propagating southerly surges within the summertime marine layer off California and Oregon. Preprints, 12th Symp. on Boundary Layers and Turbulence, Vancouver, BC, Canada, Amer. Meteor. Soc., 346-347.
Beardsley, R. C., C. E. Dorman, C. A. Friehe, L. K. Rosenfield, and C. D. Wyant, 1987: Local atmospheric forcing during the Coastal Ocean Dynamics Experiment 1: A description of the marine boundary layer and atmospheric conditions over northern California upwelling region. J. Geophys. Res., 92, 1467-1488.

Bond, N. A., C. A. Mass, and J. E. Overland, 1996: Coastally trapped wind reversals along the United States west coast during the warm season. Part I: Climatology and temporal evolution. Mon. Wea. Rev., 124, 430-445.

Dorman, C. E., 1985: Evidence of Kelvin waves in California's marine layer and related energy generation. Mon. Wea. Rev., 113, 827-839.

Leon, D., G. Vali, and M. Lothon, 2006: Dual-Doppler analysis in a single plane from an airborne platform. J. Atmos. Oceanic Technol., 23, 3-22.

Mass, C. F., and M. D. Albright, 1987: Coastal southerlies and alongshore surges of the west coast of North America: Evidence of mesoscale topographically trapped response to synoptic forcing. Mon. Wea. Rev., 115, 1707-1738.

_ , and N. Bond, 1996: Coastally trapped wind reversals along the west coast during the warm season. Part II: Synoptic evolution. Mon. Wea. Rev., 124, 446-461.

Nuss, W. A., 2007: Synoptic-scale structure and character of coastally trapped wind reversals. Mon. Wea. Rev., 135, 60-81.

- , and Coauthors, 2000: Coastally trapped wind reversals: Progress toward understanding. Bull. Amer. Meteor. Soc., 81, 719-743.

Parish, T. R., 2000: Forcing of the summertime low-level jet along the California coast. J. Appl. Meteor., 39, 2421-2433.

_ M. D. Burkhart, and A. R. Rodi, 2007: Determination of the horizontal pressure gradient force using global positioning system onboard an instrumented aircraft. J. Atmos. Oceanic Technol., 24, 521-528.

Pomeroy, K. R., and T. R. Parish, 2001: A case study of the interaction of the summertime coastal jet with the California topography. Mon. Wea. Rev., 129, 530-539.

Ralph, F. M., L. Armi, J. M. Bane, C. E. Dorman, W. D. Neff, P. J. Neiman, W. A. Nuss, and P. O. G. Persson, 1998: Observations and analysis of the 10-11 June 1994 coastally trapped disturbance. Mon. Wea. Rev., 126, 2435-2465.

_ , P. J. Neiman, J. M. Wilczak, P. O. G. Persson, J. M. Bane, M. L. Cancillo, and W. Nuss, 2000: Kelvin waves and internal bores in the marine boundary layer inversion and their relationship to coastally trapped wind reversals. Mon. Wea. Rev., 128, 283-300.

Rogers, D. P., and Coauthors, 1998: Highlights of Coastal Waves 1996. Bull. Amer. Meteor. Soc., 79, 1307-1326.

Skamarock, W. C., R. Rotunno, and J. B. Klemp, 1999: Models of coastally trapped disturbances. J. Atmos. Sci., 56, 3349-3365.

Thompson, W. T., T. Haack, J. D. Doyle, and S. D. Burk, 1997: A nonhydrostatic mesoscale simulation of the 10-11 June 1994 coastally trapped wind reversal. Mon. Wea. Rev., 125, 32113230.

— S. D. Burke, and J. Lewis, 2005: Fog and low clouds in a coastally trapped disturbance. J. Geophys. Res., 110, D18213, doi:10.1029/2004JD005522.

vanZanten, M. C., B. Stevens, G. Vali, and D. H. Lenschow, 2005: Observations of drizzle in nocturnal marine stratocumulus. $J$. Atmos. Sci., 62, 88-106.

Zemba, J., and C. A. Friehe, 1987: The marine boundary layer jet in the coastal ocean dynamics experiment. J. Geophys. Res., 92, 1489-1496. 